UNIVERSIDADE DE SÃO PAULO

ESCOLA DE DEDUCAÇÃO FÍSICA E ESPORTE

\title{
EFEITO DA MODIFICAÇÃO DA TAREFA NA BRAÇADA DO NADO CRAWL EM INDIVÍDUOS COM NÍVEIS DE HABILIDADES DISTINTOS
}

Fabrício Madureira Barbosa

SÃO PAULO

2006 
Efeito da modificação da tarefa na braçada do nado crawl em indivíduos com níveis de habilidades distintos

\author{
FABRÍCIO MADUREIRA BARBOSA
}

\begin{abstract}
Dissertação apresentada à Escola de Educação Física e Esporte da Universidade de São Paulo, como requisito parcial para a obtenção do grau de Mestre em Educação Física.
\end{abstract}

ORIENTADOR: PROFA. DRA. ANDREA MICHELE FREUDENHEIM 


\section{AGRADE CIME NTOS}

Como em uma abordagem sistêmica, onde o mundo é visto em termos de relações e de integração, minha caminhada até este ponto, só foi possível por que pessoas fantásticas me auxiliaram de formas distintas, e a elas, eu serei eternamente grato.

A minha orientadora Profa. Dra. Andréa Michele Freudenheim, por toda sua compreensão, paciência, motivação e dedicação, neste tão desejado sonho.

A todos os membros do LACOM, por suas participações, idéias e questionamentos. Em especial, ao grande fundador e visionário Prof. Dr. Go Tani.

À Profa. Dra. Suely dos Santos e Profa. Dra. Lilian Teresa Bucken Gobbi, pelas contribuições a mim e ao projeto.

Aos amigos e irmãos Henrique França, Daniel Guedes Gollegã, Marcel Rocha, Tathiane Martins e Thaís Medeiros por todo apoio no trabalho de coleta e tabulação dos dados e principalmente, pela retaguarda oferecida ao pequeno Jonathan.

Aos amigos que fizeram e ainda fazem parte da equipe Magic Team.

A todos os funcionários da USP, integrados ao setor de pós-graduação pela paciência e atenção despendida.

A polícia rodoviária do estado de São Paulo (Km40-NORTE), por seu apoio e atenção nas pequenas paradas para um breve cochilo, quando o cansaço era quase uma arma, na subida da serra.

Aos homens que através de suas palavras e ações me incentivaram, ainda na graduação, na busca pelo conhecimento Macello Àrias Dias Danucalov, Dilmar Pinto Guedes Jr. e Tácito Pessoa de Souza Jr.

Aos amigos Rubens Viegas, Dirceu Leal, Luiz Alberto, João Batista (Bata), Robério Maciel e Wilson (Sanny) que hoje tenho o privilégio de compartilhar mais este momento, porque foram pessoas imprescindíveis na abertura de possibilidades.

A minha segunda família Cassia Cristina (a desencadeadora de tudo isto) e nosso filho Jonathan, por vosso amor, compreensão e paciência neste projeto.

A minha primeira família Marli, Armando, Alexander (in memorian), Nicolas e Giuliano, saibam que através de suas palavras e atitudes, nasceram as lições mais intensas da minha vida. Por tudo que vivi e ainda irei viver, sou eternamente grato. 


\section{SUMÁRIO}

Página

LISTA DE TABELAS....................................................................

LISTA DE ANEXOS...................................................................... vii

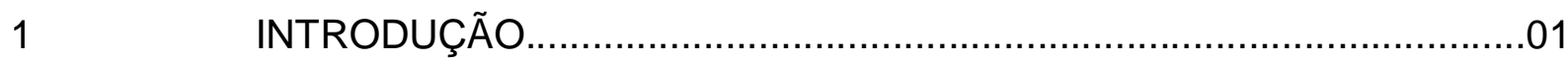

2 PROCESSO DE AQUISIÇÃO DE HABILIDADES MOTORAS.................02

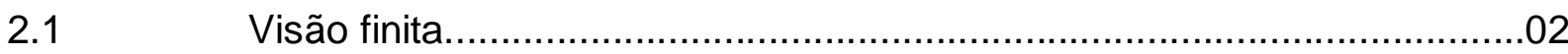

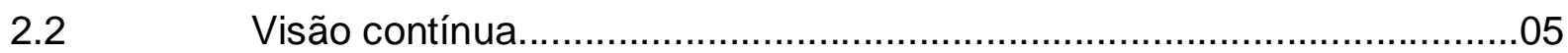

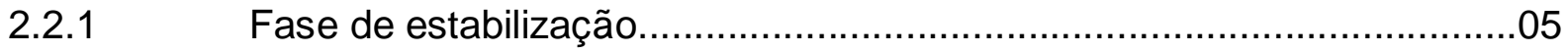

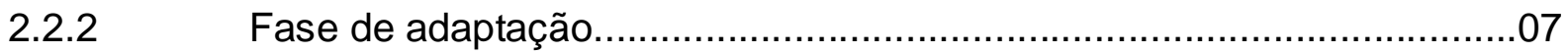

3 A HABILIDADE NADAR

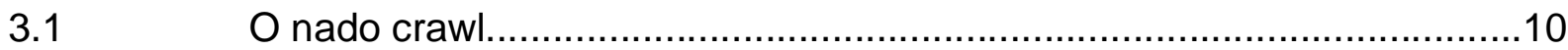

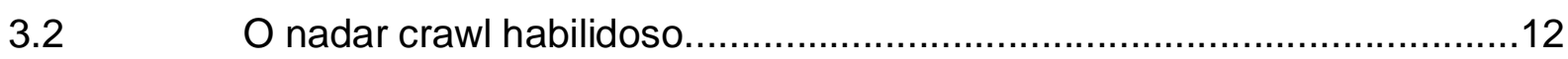

4 OBJETIVO

$5 \quad$ MÉTODO

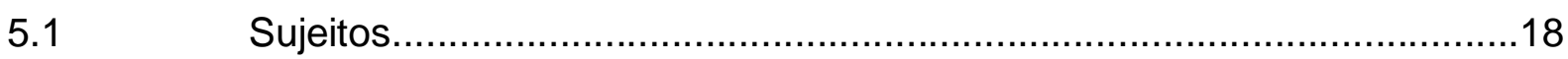

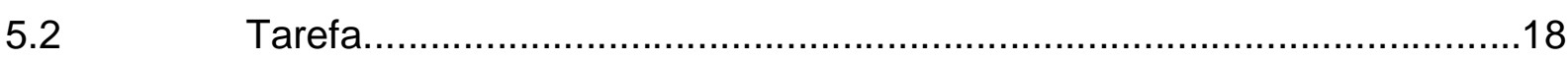

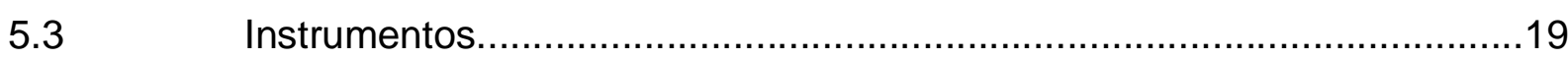

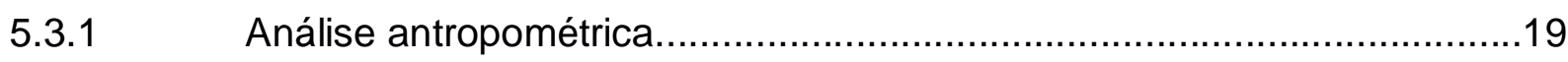

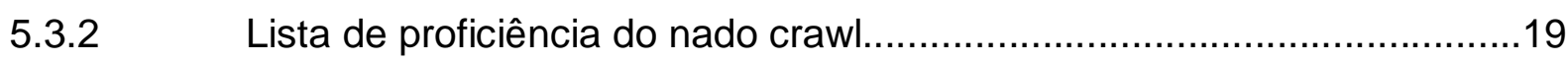

5.3.3 Carro de filmagem dinâmica aquática........................................................

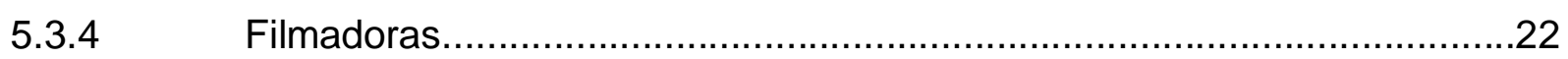

5.3.5 Tinta para a marcação dos pontos anatômicos ......................................22

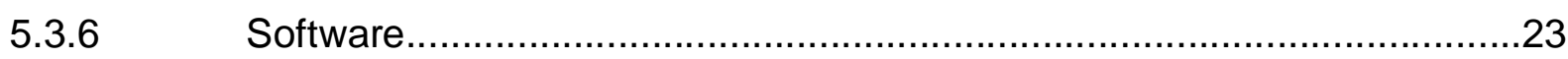

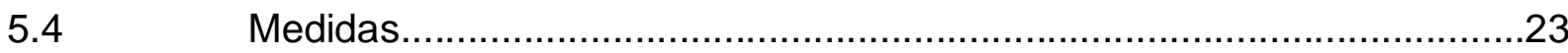

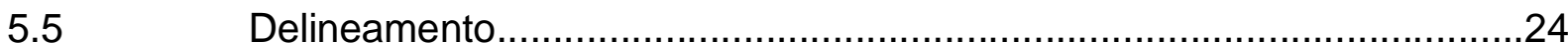

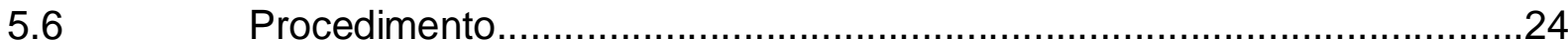

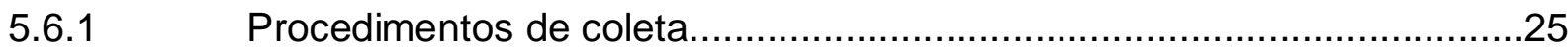

5.6.2 Procedimentos para constituição dos grupos........................................25

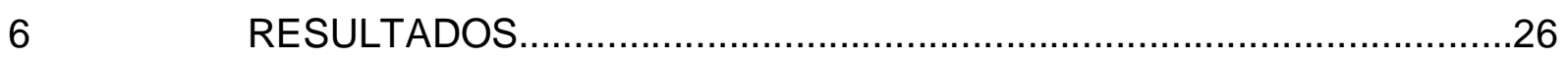

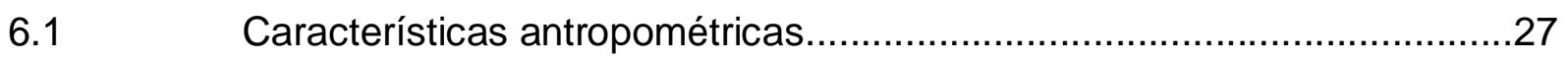

6.2 Características do desempenho.......................................................28 
6.3 Aspectos invariantes e variantes do nado..........................................30

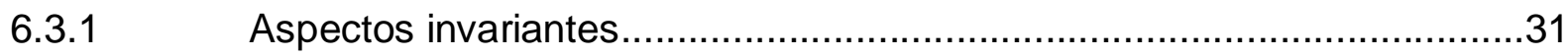

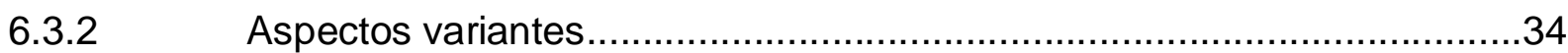

DISCUSSÃO

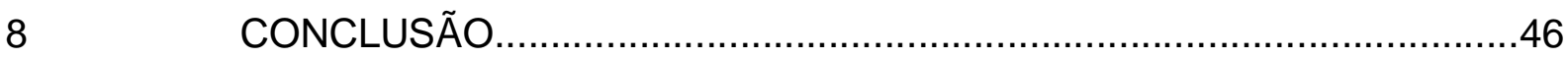

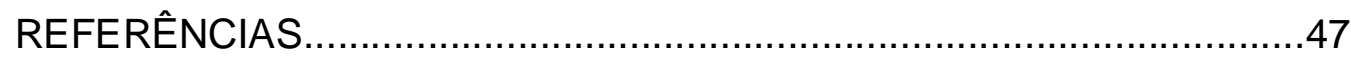

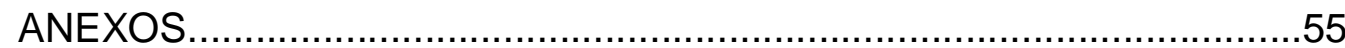




\section{LISTA DE TABELAS}

Página

TABELA 1 - Apresentação da significância da diferença entre avaliadores, coeficiente de correlação intraclasse e erro típico da medida.

TABELA 2 - Descrição das características antropométricas dos grupos mais e menos habilidosos.

TABELA 3 - Descrição das características do rendimento de nado. 29

TABELA 4 - Descrição do comportamento dos aspectos invariantes das braçadas de ambos os braços, para os grupos mais e menos habilidosos .32

TABELA 5 - Descrição da variabilidade observada nos aspectos invariantes em três ciclos de braçadas, para ambos os braços, nos grupos mais e menos habilidosos .33

TABELA 6 - Descrição do comportamento dos aspectos variantes do nado para o braço direito

TABELA 7 - Descrição do comportamento das características variantes do nado para o braço esquerdo.

TABELA 8 - Descrição do comportamento das características variantes do nado para o ciclo total.

TABELA 9 - Descrição da variabilidade observada nas características variantes em três braçadas para o braço direito.

TABELA 10 - Descrição da variabilidade observada nas características variantes em três braçadas para o braço esquerdo.

TABELA11 - Descrição da variabilidade observada nas características variantes em três ciclos de braçadas totais 


\section{LISTA DE ANEXOS}

ANEXO I - $\quad$ Termo de consentimento livre e esclarecido...................................55

ANEXO II - $\quad$ Instrumento para análise do nível de proficiência do nado crawl.........58

ANEXO III - $\quad$ llustrações do aparelho usado para captar as imagens, aérea e subaquática, para a análise qualitativa do nado

ANEXO IV - Descrição do aparelho usado para captar as imagens aérea e subaquática, para a análise qualitativa do nado.

ANEXO V - Distribuição dos aspectos invariantes das braçadas do braço direito nas fases aérea e aquática, para ambos os grupos

ANEXO VI - Distribuição dos aspectos invariantes das braçadas do braço esquerdo nas fases aérea e aquática, para ambos os grupos

ANE XO VII - Variabilidade dos aspectos invariantes do braço direito nas fases aérea e aquática em ambos os grupos.

ANEXO VIII - Variabilidade dos aspectos invariantes do braço esquerdo nas fases aérea e aquática em ambos os grupos.

ANEXO IX - Distribuição aspectos variantes do braço direito para as fases aérea e aquática de ambos os grupos.

ANEXO X - Distribuição aspectos variantes do braçada direita total.....................68

ANEXO XI - Distribuição aspectos variantes do braço esquerdo para as fases aérea e aquática de ambos os grupos 69

ANEXO XII - Distribuição aspectos variantes do braçada esquerda total.................70

ANE XO XIII - Distribuição aspectos variantes do ciclo total..................................71

ANE XO XIV - Variabilidade dos aspectos variantes da fase aérea e aquática do braço direito para ambos os grupos.

ANE XO XV - Variabilidade dos aspectos variantes do braço direito total.................73

ANEXO XVI - Variabilidade dos aspectos variantes da fase aérea e aquática do braço esquerdo para ambos os grupos

ANEXO XVII - Variabilidade dos aspectos variantes do braço esquerdo total. .75

ANE XO XVIII - Variabilidade dos aspectos variantes do ciclo total das braçadas.......76 
RESUMO

\title{
EFEITO DA MODIFICAÇÃO DA TAREFA NA BRAÇADA DO NADO CRAWL EM INDIVÍDUOS COM NÍVEIS DE HABILIDADES DISTINTOS
}

\author{
Autor: FABRÍCIO MADUREIRA BARBOSA \\ Orientadora: PROFA. DRA. ANDREA MICHELE FREUDENHEIM
}

Em habilidades como o nadar tem se creditado o sucesso à consistência do comportamento, negligenciando o papel da flexibilidade. Nesse sentido, com o objetivo de investigar o efeito da modificação da tarefa na braçada do nado crawl em indivíduos em níveis de habilidades distintos, partiu-se da visão de complementaridade entre consistência e flexibilidade do comportamento motor habilidoso. Crianças (42), com média de 8,7 anos de idade, com domínio do nado crawl, participaram do experimento. Usando o instrumento de análise do nível de proficiência do nado crawl, dois grupos, de 15 sujeitos cada, em níveis de habilidades distintos foram formados. Medidas de aspectos invariantes e variantes foram utilizadas para analisar as braçadas na tarefa de deslocar-se 30 metros em três velocidades. Segundo os resultados, os nadadores mantiveram a organização temporal da braçada (OTB) nas três condições experimentais; o grupo mais habilidoso $(+\mathrm{H})$ apresentou a OTB mais estável; e, as alterações de desempenho foram efetuadas, exclusivamente a partir de ajustes dos aspectos variantes das braçadas. Em função dos resultados conclui-se que a aquisição do nadar, vista como um processo contínuo, envolve a formação de representações mentais que asseguram tanto a consistência (aspectos invariantes) como a flexibilidade (aspectos variantes) da braçada e, que sua complexidade está associada ao nível de habilidade dos nadadores.

Palavras chaves: aprendizagem motora, natação, processo adaptativo 


\title{
ABSTRACT
}

\section{EFFECTS OF THE MODIFICATION OF THE TASK IN THE FRONT CRAWL STROKE IN INDIVIDUALS WITH DISTINCT LEVELS OF SKILL}

\author{
Author: FABRÍCIO MADUREIRA BARBOSA \\ Adviser: PROFA. DRA. ANDREA MICHELE FREUDENHEIM
}

In skills, as swimming, there has been credit to the success of the consistency of behaviour neglecting the role of flexibility. In this way with the objective of investigating the effect of the modification of the task in the front crawl stroke in individuals with distinct levels of skill we launched from the point that consistency and flexibility complement each other in the skilful motor behaviour. Children (42), with an average age of 8.7 with the skill of swimming crawl participated in the experiment. Using the analysis instrument of proficiency level of the crawl style, two groups of 15 subjects each, with distinct levels of ability were formed. Measures of variant and invariant aspects were used to analyze the stroke of drifting 30 meters in three velocities. According to the results the swimmers maintained the temporal organization of the stroke (TOS) in three experimental conditions; the more skilful group presented the more stable TOS; and the alterations of the performance were made exclusively from the adjustments of the variant aspects of the strokes. Due to the results it was concluded that the acquisition of swimming seen as a continuous process, involves the formation of mental representations that assure not only consistency (invariant aspects) but also the flexibility (variaant aspects) of the stroke and that its complexity is associated to the level of skill in the swimmers.

Key words: motor learning, swimming, adaptative process 


\section{INTRODUÇÃO}

Flexibilidade e consistência são características do comportamento motor habilidoso (CONNOLLY, 1977; GLENCROSS, 1980). Para compreender a natureza desses comportamentos, há a necessidade de distinguir movimento de ação. NEWELL (1978) define movimento como o deslocamento do corpo e membros produzido como conseqüência do padrão espacial e temporal de contrações musculares. Por isso movimentos podem ser descritos com relativa precisão. Já a ação, é realizada com base na intenção e no objetivo que se pretende alcançar.

Para CONNOLLY (1975) a flexibilidade do comportamento motor habilidoso advém da falta de identidade entre movimento e ação, ou seja, da capacidade de realizarmos a mesma ação através de diferentes movimentos, bem como, de realizarmos diferentes ações através de movimentos semelhantes. Por exemplo, um nadador habilidoso pode percorrer os 25 metros de uma piscina semi-olímpica usando movimentos característicos do nado crawl, costas ou nados híbridos. Por outro lado, o nadador pode através de movimentos semelhantes executar diferentes ações. Desta forma, fazendo uso do mesmo padrão de nado, ele pode deslocar-se submersamente, pegar um objeto no fundo da piscina ou mesmo nadar entre obstáculos. Mas além de flexível, o comportamento motor habilidoso deve ser consistente, isso significa que sempre que necessário, a ação executada implica em resposta apropriada para a solução do problema motor apresentado. Sendo assim, deve-se desenvolver um controle confiável no sentido de uma possível repetição de seu padrão. Por exemplo, quando o nadador se aproxima da parede da piscina ele deve efetuar a virada olímpica do nado crawl que é caracterizada, pela realização de movimentos entorno dos eixos horizontal e latero-lateral do seu corpo. Entretanto, o cansaço diminui a freqüência e o comprimento de suas braçadas, o que inviabiliza a utilização sempre do mesmo braço como último agente propulsivo. Como se não bastasse, a velocidade de deslocamento, também diminuí em função da distância percorrida. Desta forma, a velocidade de abordagem e a flexão das articulações (coluna, quadril, joelho e tornozelo), precisam ser constantemente ajustadas para que o nadador consiga realizar a virada. Portanto, o comportamento do nadador deve ser flexível, ou seja, ele deve ser capaz de ajustar seus movimentos às constantes modificações das condições de execução da tarefa. Entretanto, o seu comportamento, também deve ser consistente, 
isto é, em função dos ajustes ele deve ser capaz de realizar o padrão da virada, a cada aproximação da borda.

Portanto, quando estudamos comportamento motor habilidoso devemos considerar a existência de flexibilidade e consistência como características complementares. Aspectos como o timing relativo, sequenciamento e força relativa que são mantidos relativamente invariantes ao longo das tentativas (SCHMIDT 1980, 1985) garantem a consistência do comportamento motor habilidoso. Por outro lado, aspectos como tempo de movimento, força total e seleção dos músculos, que variam para atender as demandas específicas da tarefa SCHMIDT $(1980,1985)$ asseguram a flexibilidade do comportamento.

No entanto, em habilidades como o nadar para as quais a velocidade máxima é a meta a ser alcançada, de forma geral, credita-se o sucesso à consistência do comportamento. Nesses casos, visa-se a capacidade do nadador conseguir deslocar-se mais rapidamente possível, sempre que desejado. Esse tipo de fenômeno equivale a olhar somente "um lado da moeda". Nesse sentido, o presente estudo tem como objetivo investigar a habilidade do nadar a partir da visão de complementariedade entre as características consistência e flexibilidade do comportamento motor habilidoso.

\section{PROCESSO DE AQUISIÇÃO DE HABILIDADES MOTORAS}

\subsection{Visão finita}

As formulações teóricas tradicionais da área de Aprendizagem Motora (ADAMS, 1971; SCHMIDT, 1975), consideram apenas uma parte do processo, que é a estabilização do desempenho via feedback negativo. A seguir discutiremos três modelos de equilíbrio reconhecidos na literatura, que foram propostos por FITTS e POSNER (1967); ADAMS (1971) e GENTILE (1972).

Para FITTS e POSNER (1967), o processo de aprendizagem motora compreende três fases: 1) Fase cognitiva (inicial) - fase em que os indivíduos apresentam desempenho inconsistente, grande quantidade de erros grosseiros e não possuem capacidade de se auto-corrigir, mesmo quando cientes do que exatamente deve ser feito; 2) Fase associativa (intermediária) - Nesta fase em comparação a anterior, os aprendizes tendem a cometer erros menos grosseiros, desenvolver as capacidades de detectar e de eliminar esses erros, 
e desta forma, aumenta a interação entre o "que" fazer e o "como". Entretanto, quando realizam a habilidade motora, apresentam padrões ainda pouco consistentes; 3) Fase autônoma (final) - nesta fase os aprendizes apresentam desempenho mais consistente e preciso, pois são capazes de reconhecer e corrigir seus próprios erros.

Já, para ADAMS (1971), o processo de aquisição de habilidades motoras compreende dois estágios: 1) Estágio verbal-motor - neste estágio os indivíduos apresentam erros grosseiros e frequentemente, têm necessidade de verbalizar previamente as ações, e os ajustes para a melhor realização da tarefa dependem do conhecimento de resultado (CR). O CR é considerado uma informação a partir da qual o iniciante deve elaborar hipóteses e estratégias, com o intuito de, nas tentativas subseqüentes, apresentar respostas diferentes das anteriores, com as quais não alcançara a meta pretendida. Considera-se o final do estágio verbal-motor, quando o indivíduo, depois de ter realizado muita prática com $\mathrm{CR}$, consegue efetuar sucessivas respostas corretas; 2) Estágio motor este estágio é caracterizado como a fase final do processo de aquisição de habilidades motoras. Nele, a correção de erros torna-se mais efetiva, o que potencializa o sujeito a continuar aprendendo sem a utilização do CR, caracterizando assim, comportamentos automatizados.

Portanto, as descrições do processo de aquisição de habilidades motoras de FITTS e POSNER (1967) e ADAMS (1971) são similares, pois consideram os processos cognitivos como centrais no seu início e o entendem como finito, sendo a automatização seu produto final.

No contexto do ensino GENTILE (1972) apresentou uma descrição diferenciada do processo de aprendizagem motora. A autora sugere que o processo de aquisição de habilidades motoras, compreende duas fases: 1) Fase de obtenção da idéia do movimento - nesta fase o indivíduo deve obter uma idéia geral sobre o que necessita ser executado, isto é, o padrão do movimento, e em seguida deve procurar atingir a meta mediante a execução de movimentos conforme o planejado. O final desta fase se dá quando o aprendiz consegue criar uma associação entre meio-fim, isto é, entre a programação e a execução da tarefa; 2) Fase de fixação e diversificação - nesta fase a autora sugere que dependendo da natureza da habilidade (aberta ou fechada), deve-se enfatizar a fixação ou a diversificação do comportamento. Nas habilidades fechadas, as ações são realizadas em ambientes de alta previsibilidade, onde os estímulos relevantes não se modificam, exemplo: 
o salto do bloco de partida em uma prova natatória. Nesse caso o processo de aquisição de habilidades motoras se assemelha ao dos modelos anteriores, onde o aprendiz deve, através da prática constante, experimentar e selecionar a forma mais eficaz de alcançar a meta. No caso das habilidades abertas, as ações são realizadas em ambientes de baixa previsibilidade, portanto, nos quais os estímulos relevantes mudam durante a execução da tarefa, por exemplo, nadar no mar. Nesta situação o aprendiz deve aprender a ajustar suas respostas às condições ambientais. Nesse caso, na segunda fase do processo de aquisição de habilidades motoras, o indivíduo deve ser orientado a desenvolver um vasto repertório de respostas para poder diversificar a maneira de alcançar a meta desejada.

Portanto, diferente de FITTS e POSNER (1967) e ADAMS (1971), GENTILE (1972) alerta para a necessidade de distinguir o processo de aquisição em virtude da natureza da habilidade a ser adquirida, isto é, fechada ou aberta. Para a autora no caso de habilidades fechadas, após o aprendiz conseguir realizar a tarefa, o foco deve estar concentrado na maximização da consistência. Entretanto, nas habilidades classificadas como abertas, a partir desta conquista, o foco principal deve ser a flexibilidade do comportamento. No entanto, as três descrições consideram apenas uma parte do processo de aquisição de habilidades motoras que é a estabilização do desempenho alcançado via feedback negativo. Sendo assim, estes modelos concebem o processo de aquisição de habilidades motoras, como finito, sendo a automatização do comportamento seu produto final (TANI, 1989, 1995).

Mas, em se considerando a aquisição de habilidades motoras como um processo de início e fim definidos, como explicar o estudo clássico de aprendizagem realizado por CROSSMAN (1959) no qual foi demonstrado que indivíduos conseguem melhorar seu desempenho em habilidade de manipulação, mesmo após décadas de prática? Ainda, como explicar o fato de seres humanos quebrarem recordes, como por exemplo, ocorreu nas diversas provas de natação nesta última olimpíada? Estes dois exemplos mostram o quão improvável é o fato de o processo de aquisição de habilidades motoras ser finito, o que ao mesmo tempo desencadeia a necessidade de buscarmos uma alternativa, para explicar o fenômeno aprendizagem motora. 


\subsection{Visão contínua}

Recentes meta-teorias da ciência enfatizam que em sistemas abertos, a formação de novas estruturas pressupõe instabilidade, portanto quebra da estabilidade do sistema (BERTALANFFY, 1977). Nessa perspectiva TANI (1995) propõe que a aquisição de habilidades motoras pode ser melhor explicada se observada como um processo cíclico e dinâmico de instabilidade-estabilidade-instabilidade, que resulta em crescente complexidade. Nesse sentido, CHOSHI e TANI ${ }^{1}$ (citados por TANI, 1995), TANI (1982, 1989) e TANI, BASTOS, CASTRO, JESUS, SACAY e PASSOS (1992) têm proposto um modelo de não equilíbrio em aprendizagem motora, composto por duas fases, que são: estabilização e adaptação.

\subsubsection{Fase de Estabilização}

Modelos, que concebem o processo de aquisição de habilidades motoras como gradativo e finito, vêm à estabilização como a última fase do processo de aquisição (ADAMS, 1971; FITTS \& POSNER, 1967; GENTILE, 1972). No entanto, em um modelo de não equilíbrio em aprendizagem motora, a estabilização deve ser compreendida, como um estado temporário, no processo contínuo de aumento de complexidade.

Segundo TANI (1995, 2005), ao longo do processo de estabilização o aprendiz se torna capaz de executar os componentes de uma habilidade, por exemplo, no caso do salto em distância: corrida; impulsão; fase aérea e aterrissagem, em interação espaço-temporal. Entretanto, o autor também propõe que os componentes da habilidade, não podem ser vistos como unidades rígidas e estereotipadas, mas algo que permite certa extensão de variações como resultados de mudanças nos parâmetros tempo, força e deslocamento, aplicados ao padrão básico. Por exemplo, a corrida no salto em distância pode ser realizada muito rápida, rápida, lenta ou muito lenta. As velocidades são diferentes manifestações de um mesmo padrão de corrida. Este padrão corresponde aos aspectos que permanecem invariantes ao longo das tentativas, ao passo que as variações dos parâmetros como tempo, força e distância são responsáveis pelos aspectos que mudam de tentativa a tentativa, embora sem

K. CHOSHI, G. TANI. Stablesystem and adaptative system in motor learning. In: Japanese Association of Biomechanics (Ed.). The 
science of movement. V. Tokyo: Kyorin, 1983. (in Japanese)

causar perda da identidade do padrão. Assim, a padronização espaço-temporal, garante a consistência do comportamento e a possibilidade de variar os parâmetros do movimento variantes, assegurando a capacidade do indivíduo de se ajustar às demandas específicas da tarefa, ou seja, garante a flexibilidade. Portanto, a fase de estabilização deve ser compreendida como uma fase no processo de aquisição de habilidades motoras ao final da qual, o aprendiz apresenta comportamentos com consistência e flexibilidade ao mesmo tempo.

FREUDENHEIM (1999) realizou dois experimentos visando estudar a fase de estabilização nesta abordagem contínua do processo de aquisição de habilidades motoras. Em ambos, o instrumento utilizado foi uma caneta sem fio e uma mesa digitalizadora sensível à pressão da caneta (Quora Cordless modelo QC-A4 da TDS Card-graphics). A tarefa solicitada foi reproduzir um padrão gráfico. Nos dois experimentos, a análise inferencial detectou que a variabilidade nas medidas que correspondem aos aspectos invariantes (tamanho relativo, tempo de pausa relativo tempo do movimento relativo e sequenciamento), diminuiu demonstrando que ao longo da fase de estabilização ocorreu a padronização espaço-temporal. Nas medidas correspondentes aos aspectos variantes como a variabilidade do tempo total de pausa, do tamanho total e do tempo total do movimento, também ocorreu diminuição da variabilidade ao longo das tentativas de prática. No entanto, essa diminuição não significou uma eliminação da variabilidade, pois mesmo após prática extensiva, certo nível de variabilidade foi mantido. Em conjunto, os resultados deste trabalho permitiram, a princípio, deduzir que existe associação entre a melhora do desempenho e a diminuição da variabilidade.

Como descrito acima, o estudo de FREUDENHEIM (1999), demonstrou que a melhora do desempenho da fase de estabilização foi acompanhada pela diminuição da variabilidade, mas não pela sua eliminação. Mas, o que a variabilidade que permanece após a estabilização do desempenho pode significar? MANOEL e CONNOLLY (1995) propõem a existência de dois tipos de variabilidade, que são a variabilidade de erro, sobre a qual o indivíduo não tem domínio e a variabilidade funcional, que está sob o controle do indivíduo. A primeira é inerente ao sistema e esta presente a cada movimento, potencializando negativamente a qualidade de um determinado padrão, não sendo eliminada nem controlada. Já a variabilidade funcional, é segundo os autores um aspecto central ao processo de aquisição de habilidades motoras, pois novos padrões motores 
emergem devido à instabilidade do sistema.

\subsubsection{Adaptação}

Para TANI (1995) o processo de adaptação refere-se à formação de estruturas mais complexas a partir daquelas existentes mediante uma quebra da estabilidade seguida por outro regime de estabilidade, mas agora, em um nível superior de complexidade. Assim, esta fase diz respeito à adaptação a novas situações ou tarefas motoras com base em habilidades já adquiridas. TANI (1995) sugere que a adaptação pode ser feita de forma passiva ou ativa. Quando ocorre por meio da própria flexibilidade do sistema, isto é, via ajuste dos aspectos variantes, esta adaptação é considerada paramétrica ou passiva. Entretanto, se o aprendiz for submetido a uma perturbação que ultrapasse a flexibilidade do sistema, podem-se esperar dois tipos de respostas, que são: 1) adaptação à perturbação por meio da reorganização da estrutura já existente, o que foi denominado de adaptação estrutural ou ativa. Este tipo de adaptação tem sido observada em alguns nadadores de

elite, que conseguem reorganizar a estrutura do seu nado frente a perturbações (CHOLLET, CHARLIES \& CHATARD, 2000) ou 2) adaptação a partir da emergência de uma estrutura nova, que é denominada de adaptação auto-organizacional.

Para TANI, FREUDENHEIM, MEIRA JÚNIOR e CORRÊA (2004), esta visão dinâmica do processo de aquisição de habilidades motoras, é acompanhada pelo surgimento de novas questões. Se a aprendizagem depois da estabilização pressupõe instabilidade do sistema, torna-se importante então, a investigação dos mecanismos pelos quais o sistema se adapta e isto parece depender de duas condições básicas, que são: a-) quanta perturbação é introduzida no sistema e b-) quando a perturbação é inserida. Com relação à primeira condição, podemos especular que se a perturbação for muito grande, o sistema pode entrar em colapso, o que implicaria na incapacidade de o mesmo lidar com a tarefa, portanto a necessidade de formação de uma nova estrutura. Por outro lado, se a perturbação for muito pequena, a mesma pode não constituir-se de um agente impulsionador do processo de mudança em direção ao aumento da complexidade. Para a condição (b) o problema é se a estabilização constitui-se de um pré-requisito para a ocorrência da adaptação se sim, em que nível de redundância a estabilização deve ocorrer para que a mesma tenha o potencial de favorecer a adaptação. Nesses dois casos de 
adaptação, há um aumento de complexidade no sistema em que ele ganha características novas sem perder as anteriores. Sendo assim, quando se entende a aquisição como processo adaptativo, a importância da perturbação parece intrínseca, pois em função dela o sistema tem que buscar uma nova organização para enfrentar a perturbação.

UGRINOWITSCH (2003), utilizando uma tarefa complexa de timing antecipatório, mostrou que o processo de adaptação pode estar relacionado ao tipo de perturbação (perceptiva, motora e perceptivo-motora) e ao nível de estabilização do desempenho (préestabilização, estabilização e superestabilização). Os resultados mostraram que no nível de pré-estabilização do desempenho, não houve adaptação, pois a estrutura não havia sido formada em conseqüência da quantidade insuficiente de prática para a tarefa utilizada. Com a estabilização do desempenho, entretanto, houve adaptação às perturbações perceptiva motora, mas não à perturbação perceptivo-motora. Já na superestabilização, os indivíduos estudados adaptarem-se aos três tipos de perturbação. Os resultados destes experimentos mostraram a possível existência de uma hierarquia de perturbações, sendo a perceptivo, menor e a perceptivo-motora maior. O estudo mostrou ainda, que na fase de pré-estabilização do desempenho, a variabilidade não diminuiu. Quando os voluntários atingiram a estabilização do desempenho, a variabilidade nas tentativas iniciais e finais da fase de estabilização foi à mesma. Entretanto, na fase de adaptação, a variabilidade diminuiu logo nas tentativas iniciais. Na superestabilização do desempenho, a variabilidade do comportamento, foi a mesma da estabilização, tendo novamente diminuído na fase de adaptação. Estes resultados indicam que a variabilidade desempenha papéis diferentes em razão do nível de estabilização do desempenho. Isto é, na fase inicial é prejudicial à adaptação, mas após a estabilização do desempenho pode ser fonte de adaptabilidade.

Poucos estudos têm analisado o efeito da organização da prática com base na abordagem do processo adaptativo. CORRÊA (2001) investigou os efeitos de diferentes estruturas de prática no processo adaptativo na aquisição de habilidades motoras em três experimentos. No experimento 1, a prática variada referiu-se ao componente perceptivo da tarefa, e os resultados, mostraram que o desempenho foi semelhante para todos os grupos na fase de adaptação. Mas, o grupo de prática constante-aleatória adaptou-se sem modificação da estrutura e os demais grupos adaptaram-se pela modificação de aspectos invariantes da habilidade, ou seja, via reorganização da estrutura. No experimento 2, a 
prática variada foi manipulada quanto a diferentes padrões seqüenciais de resposta. Os resultados indicaram melhor desempenho na fase de adaptação para o grupo de prática

constante-aleatória, sendo esse grupo capaz de modificar os aspectos invariantes da habilidade e diminuir sua variabilidade, diferentemente dos demais grupos. No experimento 3, a prática foi manipulada nos aspectos perceptivo e motor da tarefa de aquisição. Os resultados mostraram que houve melhor desempenho na fase de adaptação do grupo de prática constante-aleatória, o qual modificou aspectos variantes e invariantes da habilidade, mas manteve o mesmo nível de consistência da fase de estabilização, diferentemente dos demais grupos.

Portanto, segundo CORRÊA e TANI (2005) é possível pensar que a prática constante possibilita a formação do padrão de interação entre os componentes de um sistema e que a introdução de variação nos componentes com a prática aleatória possibilita que se aumente as interações entre os mesmos, sem que esse padrão perca a identidade. Em outras palavras, pode-se dizer que relativamente à aquisição de habilidades motoras, primeiramente há necessidade de se formar a estrutura da habilidade (prática constante), e posteriormente, promover sua diversificação (prática aleatória), isto possibilita flexibilidade

ao comportamento e, portanto, adaptabilidade. Mas principalmente, estes estudos demonstraram que os sistemas se adaptam via mecanismos distintos, ainda que os mecanismos pelos quais se adaptem (flexibilidade do sistema ou reorganização da estrutura) dependem de "quanta" e "quando" a perturbação é inserida (CORRÊA, 2001; UGRINOWITSCH, 2003).

\section{A HABILIDADE NADAR}

A habilidade nadar é definida como a capacidade de sustentar-se e deslocar-se sobre a água por impulso próprio (ANJOS, FERREIRA, GEISGER, MEDEIROS \& MARQUES, 2000). No meio terrestre o ser humano utiliza a superfície do solo como um suporte rígido e fixo para deslocar-se. Desta forma, quando aplicamos uma força contra o solo, a reação do mesmo é transmitida a todo o corpo, produzindo deslocamento. Já o deslocamento no meio aquático ocorre como resultante da interação dos segmentos corporais com a água, mais especificamente, o praticante, sem suporte concreto e estável, tem que produzir deslocamento no fluído móvel, utilizando a densidade e a viscosidade do 
meio na produção de propulsão, ao mesmo tempo em que tenta superar as forças resistivas opostas.

A água resiste ao movimento do nadador. Portanto, ao deslocar-se no fluído o indivíduo experimenta uma força de impedimento conhecida como arrasto (MAGLISCHO, 1999). A natureza desta força é explicada pelas propriedades físicas da água, tais como a pressão interna, densidade e viscosidade. A reação da água ao corpo se movendo, aparece como: a) forças de pressão perpendicular à sua área frontal; e b) forças de fricção atuando ao longo da superfície do corpo (VORONTSOV \& RUMYANTSEV, 2004).

Assim, a principal parte do trabalho mecânico que o nadador realiza é direcionada para superar o arrasto hidrodinâmico. Esta resistência pode ser dividida em duas categorias: passiva e ativa (KOLMOGOROV \& DUPLISHEVA, 1992). A primeira é experimentada pelo nadador quando ele realiza a largada de partida e nas impulsões da borda, sendo sua magnitude influenciada pelo fluxo da água (laminar ou turbulento); fricção do fluído com a pele (SHARP \& COSTILL, 1989); forma do corpo (TOUSSAINT \& BEEK, 1992); formação de ondas (TOUSSAINT, KNOPS, DE GROOT \& HOLLANDER, 1990) e profundidade de imersão (VORONTSOV \& RUMYANTSEV, 2004). Já o arrasto ativo, ocorre quando o praticante esta nadando, e é considerado uma função dos movimentos, bem como, da antropometria do nadador. KOLMOGOROV e DUPLISHEVA, (1992) descrevem que a relação do arrasto ativo (propulsão) e a velocidade da natação é quadrática, isto significa que o componente pressão, é o principal contribuinte para a propulsão durante a natação. Portanto, um padrão de nado que envolva uma magnitude de arrasto passivo diminuído e elevada quantidade de propulsão produzida, terá de fato como resultante, um deslocamento de grande eficiência.

\subsection{O nado crawl}

Entre os quatro nados culturalmente determinados (costas, peito, borboleta e crawl), o nado crawl é a forma de deslocamento aquático mais eficiente e, por conseguinte, a mais praticada. Eficiência em natação deve ser entendida como percorrer uma determinada distância na menor unidade de tempo.

O nado crawl é constituído por cinco componentes interelacionados, que são: ações dos braços, sincronização entre os braços, ação do tronco, ações das pernas e sincronização entre braços e respiração. 
A ação dos braços é composta por duas fases, denominadas de aquática e aérea (MAGLISCHO, 2003; SANDERS, 1999; THORNTON \& HANNULA, 2001). A primeira é subdividida em três varreduras, sendo uma não propulsiva e duas propulsivas. As duas varreduras propulsivas da fase aquática são responsáveis por até $90 \%$ da propulsão total produzida pelo nadador (BROOKS, LANCE, \& SAWHILL, 2000). Cada uma das três varreduras, deve ser executada em três direções distintas, que são: varredura para baixo (não propulsiva), composta por movimentos para trás, para baixo e para dentro; varredura para dentro (propulsiva), formada pelos movimentos para trás, para dentro e para cima e a varredura para cima (propulsiva), que é composta pelos movimentos para trás, para fora $\mathrm{e}$ para cima. Esses subcomponentes são realizados por atletas de alto nível, com variação entre os mesmos, para ângulos, comprimento e profundidade de execução. A fase aérea é subdividida em duas partes, a primeira corresponde à ruptura da superfície da água pelo cotovelo, até o mesmo, passar por cima do ombro e a segunda parte, inicia-se na passagem do cotovelo sobre o ombro até a imersão da mão na água. Liberação e ataque são as denominações usadas para caracterizar, respectivamente, a transição da fase subaquática para a fase aérea e desta última para a fase aquática.

O componente, sincronização entre os braços, pode ocorrer de três formas: alongamento, oposição e sobreposição. Para caracterizar os padrões de sincronização foi proposto o Índice de Coordenação (IdC) (CHOLLET, CHALIES \& CHATARD, 2000). Na primeira forma de sincronização o nadador mantém um IdC de percentual negativo, o que equivale a existência de uma quebra de continuidade na propulsão produzida pelos braços. Para a oposição o IdC resultante é igual a zero, o que implica em continua aceleração propulsiva. Já para a sobreposição o IdC resulta, positivo denotando assim a existência de uma ação dupla propulsão dos braços no ciclo de braçada .

Por sua vez, durante o nado crawl o tronco, deve rolar em torno do próprio eixo. Desta forma pode-se diminuir o arrasto passivo de forma, bem como maximizar a força propulsiva dos braços. Para YANAI (2003) e MAGLISCHO (1999) este rolamento oscila entre 30 e 45 graus em nadadores velocistas, já para os fundistas a oscilação esta entre 50 e 60 graus.

Já a ação das pernas, como a dos braços, pode ser dividida em duas fases, que são a propulsiva e a de recuperação. Na primeira, a direção do deslocamento da perna deve ser para trás, para baixo e para dentro. Este tipo de ação é denominado pernada de adejamento, e é conseqüência do rolamento do tronco. A freqüência das pernadas pode 
variar em função da distância da prova a ser nadada (PERSYN, DE MAYER \& VERVAEKE, 1975). Entretanto, a eficiência propulsiva da ação das pernadas no nado crawl, parece ser pouco importante (BROOKS, LANCE, \& SAWHILL, 2000). Para DESCHODT (1999), a pernada tem importância na estabilidade do rolamento, o que facilita as ações propulsivas dos braços.

O quinto componente do nado crawl, a sincronização entre os braços e a respiração, deve ocorrer da seguinte forma: a inspiração deverá iniciar-se durante o início da segunda varredura propulsiva e o retorno da face do atleta a água, deve ocorrer antes da segunda fase da recuperação (MAGLISCHO, 2003).

Vale ressaltar que o nado crawl, só pode ser efetivamente caracterizado como tal, quando há interação entre os seus cinco componentes (FREUDENHEIM, GAMA, MOISÉS, NICOLETTI \& CHEDID, 1994).

\subsection{O nadar crawl habilidoso}

Vários estudos têm sido realizados com o intuito de encontrar quais as variáveis relevantes que poderiam caracterizar um nadador como habilidoso. Entretanto, parece existir uma grande dificuldade para estabelecer estas características. Dentre as possíveis variáveis consideradas na literatura como relevantes estão: natureza genética (CORDAIN, TUCKER, MOON \& STAGER, 1990; CREIGHTON, MORGAN, BOARDLEY \& BROLINSON, 2001); aspectos fisiológicos (ZOELLER, NAGLE, MOYNA, GOSS, LEPHART \& ROBERTSON, 1998) e eficiência biomecânica (D'ACQUISTO \& BERRY, 2003; KEPPENHAM \& YANAI, 1995). No entanto, no presente estudo, serão enfocadas a consistência e a flexibilidade do nadar, pois estas, como mencionado na introdução, são características relevantes do comportamento motor habilidoso (CONNOLLY, 1977; GLENCROSS, 1980).

Os estudos que têm considerado a manutenção da consistência como uma variável relevante, levam em conta a capacidade que os nadadores têm de manter o mesmo padrão de nado durante o percurso a ser realizado (CARDELLI, CHOLLET \& LERDA, 1999; CHOLLET, PELAYO, DELAPLACE, TOURNY \& SIDNEY, 1997; CRAIG, 1986). CARDELLI, CHOLLET e LERDA (1999) analisaram o comportamento de três grupos de habilidades distintas, para os 100 metros nado crawl em velocidade máxima. O comportamento dos nadadores foi analisado a cada 25 metros da distância total. Os resultados mostraram que 
os atletas mais habilidosos também apresentavam maior estabilidade para as variáveis, velocidade de nado, tempo de virada, freqüência e comprimento das braçadas, quando comparado aos outros dois grupos. Por sua vez CHOLLET, et alii (1997) estudaram a consistência nas características das braçadas em indivíduos com diferentes níveis de habilidade. Para isto os autores filmaram e analisaram 442 nadadores, sendo que 40 destes eram de nível internacional. Com o intuito de registrar as variáveis: velocidade, freqüência de braçadas (média de ciclos por minuto para o comprimento da piscina) e o comprimento da braçada (freqüência de braçadas dividida pela distância percorrida). $O$ experimento demonstrou que nadadores campeões possuem como características a pouca alteração das variáveis estudadas para o nadar, quando analisadas as diferenças das duas metades de uma prova. CRAIG (1986) estudou grupos em níveis distintos da habilidade do nado crawl, que foram divididos por suas melhores marcas para a distância de 100 metros. Os resultados mostraram que nadadores mais habilidosos permaneciam mais tempo em apnéia durante as filipinas (deslocamentos submersos), após as viradas, e os mesmos, ainda se diferenciavam dos seus congêneres menos habilidosos, pela consistência que era mantida durante cada etapa da prova para esta variável.

Em suma, estudos demonstram que nadadores habilidosos apresentam maior consistência na manutenção de parâmetros como velocidade de deslocamento, comprimento da braçada, freqüência das braçadas, freqüência de pernadas, comprimento de distâncias com nado subaquático e freqüência respiratória. No entanto, comportamentos demasiadamente consistentes podem possuir menor capacidade de se ajustar às demandas da tarefa (FREUDENHEIM, 1999), o que inviabiliza por vezes os ajustes necessários ao nadar contínuo.

Recentemente a flexibilidade do nadar, tem sido proposta como característica de nadadores habilidosos. Esta nova abordagem teve início com o estudo de CHOLLET, CHARLIES e CHATARD (2000), cujos objetivos foram: a-) descrever uma nova ferramenta para medir a coordenação entre os braços no nado de crawl e b-) analisar a existência ou não de variações nas sincronizações entre os braços, bem como, braços e pernas para diferentes velocidades e níveis de performance. Foram analisados 43 nadadores (29 homens e 14 mulheres) em três níveis de habilidade. Os voluntários nadaram em três diferentes velocidades máximas para as distâncias de 800 metros, 100 metros e 50 metros. Os resultados foram surpreendentes. Para a velocidade de deslocamento em 800 metros a coordenação encontrada foi a de deslizamento para ambos os grupos. Entretanto, os 
nadadores do grupo mais habilidoso (G1), modificaram seu padrão de sincronização entre os braços para as velocidades de deslocamento em 100 e 50 metros, adotando o padrão de sincronização por oposição, o que não ocorreu no grupo de nadadores menos habilidosos (G3). Ainda, com o aumento da velocidade de nado, em função das menores distâncias a serem percorridas, o G1 aumentou mais o tempo relativo das fases propulsivas (40\%) do que o G3 (24\%). Finalmente, somente o G1 foi capaz de com o aumento da velocidade, diminuir o comprimento relativo da fase de recuperação. Para os autores estas modificações no padrão de sincronização permitem ao nadador hábil levar vantagem de longos períodos de aplicação de força propulsiva. Este estudo, desencadeou o interesse no meio acadêmico por uma maior compreensão dos ajustes feitos por indivíduos habilidosos, frente a diferentes condições de deslocamento.

Neste contexto, LERDA, CARDELLI e CHOLLET (2001) estudaram o comportamento do padrão respiratório de nadadores de habilidades distintas. As variáveis utilizadas foram: o tempo das fases de inspiração e expiração, bem como a capacidade de manter-se em apnéia durante as tarefas. A tarefa consistiu em nadar diferentes distâncias em velocidade máxima. Os resultados mostraram que nadadores mais habilidosos modificaram seus padrões de respiração (inspiração, expiração e apnéia), em função da distância percorrida. Por sua vez MILLET, CHOLLET, CHALIES e CHATARD (2002), realizaram um estudo comparativo da coordenação entre os braços de nadadores de elite (15) e triatletas (19). As tarefas consistiram em nadar em seis diferentes velocidades a distância de 50 metros. Os resultados mostraram que somente o grupo de nadadores ajustou a coordenação entre os braços de forma a maximizar a performance. SEIFERT, BOULESTEIX e CHOLLET (2004) utilizaram em seu experimento, sete distâncias de nado, que variavam entre 50 e 800 metros, a serem completadas em velocidade máxima. Os resultados mostraram que nadadores mais habilidosos, independentemente do gênero, possuem maior capacidade de ajustar o padrão de coordenação entre os braços em função da distância. Nas metragens mais curtas predominou a coordenação por oposição e nas mais longas, a de alongamento. Dando continuidade a essa série de estudos SEIFERT, CHOLLET e BARDY (2004) avaliaram o modo preferencial de coordenação entre os braços de 14 nadadores de elite para as distâncias de 3000, 1500, 800, 400, 200, 100, e 50 metros. Os resultados detectaram a existência de dois padrões de sincronização preferenciais: deslizamento e oposição. Ainda demonstraram a ocorrência de uma abrupta mudança na sincronização na velocidade crítica de $1.8 \mathrm{~m} . \mathrm{s}^{-1}$, a qual corresponde a 
velocidade média atingida em provas de curta duração. As mudanças de coordenação resultam da reorganização temporal de subcomponentes das braçadas, como a diminuição das fases de ataque e alongamento do braço, concomitante com o aumento das fases propulsivas da braçada em relação ao ciclo total da braçada. Para os autores estes parâmetros de controle podem ser manipulados para facilitar a emergência de modos de coordenação específicos. Com o intuito de descrever mais detalhadamente as mudanças no padrão de sincronização SEIFERT, BOULESTEIX, CARTER e CHOLLET (2005) analisaram 12 nadadores de elite na prova de 100 metros livre. O experimento foi realizado em uma piscina de 25 metros, subdividida em cinco zonas de cinco metros. Medidas como velocidade, freqüência e comprimento das braçadas, bem como, a sincronização entre os braços, foram calculados para cada zona e para cada 25 metros percorridos. Os resultados mostraram que os nadadores não só mudam seu comportamento de nadar a cada 25 metros, como também fazem ajustes a cada zona percorrida. O IdC aumentou a cada zona dos 25 metros, indicando mudanças na organização motora, particularmente aumentando o tempo da fase aquática da braçada dentro do ciclo.

Assim, apesar consistência e flexibilidade serem tidas como características complementares de ações habilidosas (CONNOLLY, 1977; GLENCROSS, 1980), os estudos citados analisaram ambas separadamente. Chama a atenção, o fato de que os estudos que procuraram caracterizar o nado crawl habilidoso terem analisado a consistência até o final da década de 90 do século passado e a flexibilidade do comportamento a partir do presente século.

No âmbito do Laboratório de Comportamento Motor da Universidade de São Paulo XAVIER FILHO, BASSO, FREUDENHEIM, SERRA e MADUREIRA (2002) e FREUDENHEIM, BASSO, XAVIER FILHO, SILVA, MADUREIRA e MANOEL (2005) têm analisado o nado crawl a partir da visão de complementariedade entre consistência e flexibilidade do comportamento. Busca-se verificar se há diferença entre grupos avançados e iniciantes em relação aos aspectos invariantes e variantes da habilidade do nadar crawl. Sendo que, os aspectos invariantes correspondem à padronização temporal do movimento, ou seja, à consistência do comportamento, enquanto que os aspectos variantes correspondem à possibilidade de parametrização e, portanto, à flexibilidade do comportamento.

Mais especificamente, FREUDENHEIM, et alii (2005) estudaram a organização temporal da braçada do nado crawl, comparando indivíduos em níveis distintos da 
habilidade. A amostra foi constituída por onze crianças, com idade entre sete e 11 anos, todas alunas regulares de um curso de natação. O nível de habilidade das crianças no nado crawl foi definido por três especialistas segundo o modelo de desenvolvimento do nadar (XAVIER FILHO, 2001). Cinco crianças constituíram o Grupo Iniciante (GI) e seis o Grupo Avançado (GA). A tarefa experimental consistiu em se deslocar na água, numa velocidade confortável, usando o nado crawl ao longo de uma distância de dez metros. Para a análise dos dados o ciclo da braçada foi dividido em duas fases: aquática e aérea. Três ciclos consecutivos de braçada realizados na etapa intermediária do deslocamento foram considerados para efeito de análise. Com o intuito de verificar se as diferenças entre os grupos se referiam, a ambos os braços, a ação das braçadas direita e esquerda foram analisadas separadamente. Desta forma, as medidas utilizadas no experimento foram: (a) desempenho global: tempo total de movimento e variabilidade do tempo total de movimento; (b) aspectos variantes da habilidade: distribuição e variabilidade do tempo absoluto de movimento das fases aquática e aérea; e (c) aspectos invariantes da habilidade: distribuição e variabilidade do timing relativo das fases aquática e aérea. $O$ timing relativo foi caracterizado como a porcentagem do tempo total de movimento (duração total do ciclo) gasto em cada fase. Os resultados do estudo mostraram que em relação ao braço direito, o ciclo da braçada das crianças avançadas foi mais rápido que o das crianças iniciantes; em relação aos componentes da braçada na fase aérea as crianças iniciantes permaneceram mais tempo e foram mais variáveis em comparação as avançadas. Nos aspectos invariantes da habilidade, foi encontrada diferença entre os grupos no timing relativo dos componentes: as crianças do GA permaneceram relativamente mais tempo na fase aquática e o timing relativo nesse componente foi mais consistente. Para o braço esquerdo, o tempo total de movimento foi diferente entre os grupos e as crianças do Gl gastaram mais tempo no ciclo do que as crianças do GA. Os componentes diferiram na sua duração entre os grupos, mas nesse caso, os tempos absolutos das fases aquática e aérea do Gl foram mais longos que os do GA. Nas medidas que correspondem aos aspectos invariantes, não foi detectada diferença significante.

Portanto nos aspectos invariantes, em relação à braçada direita, as crianças mais avançadas apresentaram uma organização temporal mais consistente que as iniciantes. Já em relação aos aspectos variantes o GA executou ciclos mais rápidos, mas, a variabilidade do tempo total de ambos os grupos foi a mesma. Em conjunto estes resultados indicam que a variabilidade do tempo total de duração do ciclo deve possuir significados diferentes para 
os grupos. A variabilidade inerente demonstrada pelo grupo de crianças avançadas pode estar associada a uma maior disponibilidade para fazer modificações no ciclo de braçadas, seja para ajustar e manter a freqüência de braçada ou para lidar com variações na tarefa. Entretanto, faltam pesquisas que testem se de fato esta variabilidade é funcional, em outras palavras, faltam estudos que investiguem o papel da variabilidade do comportamento na flexibilidade. Para estudar esta questão, faz-se necessário modificar a tarefa com o intuito de analisar seu efeito no comportamento das variáveis que correspondem aos aspectos variantes e invariantes da habilidade, de forma complementar.

\section{OBJ ETIVO}

Investigar o efeito da modificação da tarefa na braçada do nado crawl em indivíduos em níveis de habilidades distintos.

\section{MÉTODO}

\subsection{Sujeitos}

Quarenta e duas crianças, quatorze do sexo masculino e vinte e oito do sexo feminino, participaram voluntariamente do experimento. As idades variaram entre sete e 10 anos, com média de 8,7 anos e desvio padrão de 1,2 anos. A escolha desta faixa etária ocorreu: a-) em função de, nesta fase os indivíduos já apresentam organização espacial dos movimentos de acordo com a técnica que caracteriza o nado crawl (BLANKSBY, PARKER \& BRADLEY, 1995); e b-) para amenizar as influências biológicas que ocorrem no período pubertário (MALINA \& BOUCHARD, 2002). Na época da coleta, todos os voluntários estavam freqüentando programas formais de ensino do nadar tendo no mínimo, 50 aulas já freqüentadas. Mesmo assim, a execução da tarefa ofereceu risco mínimo 
relacionados a fatores físicos e/ou psicológicos. O responsável pela criança, assinou um termo de consentimento (ANEXO I), no qual constava informação detalhada acerca dos procedimentos e riscos da pesquisa, bem como de seus direitos como participante de um experimento para fins científicos. O presente trabalho foi aprovado pela Comissão de Ética e Pesquisa da Escola de Educação Física e Esporte da Universidade de São Paulo.

\subsection{Tarefa}

O experimento foi realizado em uma piscina coberta e aquecida de 25 metros de comprimento por 12,5 de largura, com profundidade de 1 metro e $30 \mathrm{~cm}$ em toda a área. Os indivíduos nadaram a distância de 30 metros, subdividida em duas piscinas de 15 metros, desta forma. A criança era posicionada em uma marca que estava a 10 metros de distância da borda da piscina. Em seguida, nadava em direção à outra extremidade, realizava a virada olímpica na parede e retornava ao ponto inicial, totalizando os 30 metros. O percurso foi realizado em linha reta. Portanto, os nadadores foram posicionados em uma raia de dois metros de largura e tem, em suas laterais, cordas com bóias flutuantes. Este material, tem como objetivo de amenizar a turbulência de superfície no meio líquido produzida pelo nadador, bem como, evitar o deslocamento do indivíduo para fora do campo de captação de imagem das filmadoras.

O deslocamento das crianças foi realizado utilizando-se do nado crawl, haja vista que este padrão de nado possui componentes claramente identificáveis, como as ações dos braços (fase aérea e aquática), que foram o centro do nosso estudo.

\subsection{Instrumentos}

\subsubsection{Análise antropométrica}

Para o registro da massa corporal foi utilizada uma balança mecânica da marca Filizola, com resolução de $100 \mathrm{~g}$ e escala variando de 0 a $150 \mathrm{Kg}$. A mesma tinha calibragem constante e foi apoiada em solo nivelado. Para a determinação da altura foi utilizado o estadiômetro standard da American Medical do Brasil com marcação de oitenta centímetros a dois metros e vinte centímetros. O aparelho possui a resolução em milímetros e tolerância de mais ou menos dois milímetros em sua medida máxima. Para a análise das 
dobras cutâneas foi utilizado o adipômetro científico sanny da American Medical do Brasil, com campo de medição de zero a setenta e oito milímetros, sua precisão é de décimos de milímetros e tolerância de erro de mais ou menos meio milímetro em sua medida máxima. Já para a análise da envergadura foi utilizada a trena antropométrica da American Medical do Brasil, com campo de uso de dois metros, resolução em milímetros e tolerância de mais ou menos dez milímetros em um metro.

\subsubsection{Lista de proficiência do nado crawl}

LANGENDORFER e BRUYA (1995) validaram uma lista de checagem, com intenção de caracterizar o desenvolvimento da habilidade nadar, instrumento este, que é composto por cinco níveis distintos. Por sua vez XAVIER FILHO (2001), sugeriu o acréscimo de mais três níveis na lista de checagem proposta por Langendorfer e Bruya. Este acréscimo, o autor considerou necessário em função de características da população nacional. No entanto, as listas propostas por estes autores foram baseadas nas fases de desenvolvimento do nadar. Nesse sentido, esses instrumentos possuem limitações para uma análise mais aprofundada do nado crawl, entre elas, poderíamos citar: a) não avaliam o nível de habilidade do sujeito no nado crawl; b) desconsideram componentes importantes do nado crawl; c) ausência da análise de relação entre os componentes; e, d) ausência da análise bilateral do nado. Para tanto, MADUREIRA, GOLLEGÃ e FREUDENHEIM (2005), propuseram um instrumento de avaliação qualitativa do nado crawl, denominado de análise do nível de proficiência do nado crawl. Baseado nas teorias vigentes da natação foi elaborado uma lista de checagem com os 82 erros mais freqüentes, classificados segundo os sub-componentes do nado em doze categorias: 1) Erros de recuperação e entrada; 2) Erros de liberação; 3) Erros de sincronização da braçada; 4) Erros de respiração; 5) Erros de sincronização entre braçada e respiração; 6) Erros de varredura para baixo; 7) Erros de varredura para dentro; 8) Erros de varredura para cima; 9) Erros de posicionamento do corpo; 10) Erros de pernada; 11) Erros de sincronização entre pernada e respiração; e, 12) Erros de sincronização entre pernada e braçada. A amostra para validação deste instrumento foi composta por sete crianças (quatro do sexo masculino e três do sexo feminino) praticantes de natação a pelo menos um ano e com média de 10,5 anos de idade, que tiveram seus deslocamentos filmados (imagens aérea e subaquática) e analisados. A tarefa foi constituída de 15 metros de nado em velocidade natural, virada e, para possibilitar 
a análise bilateral do nado, mais 15 metros de nado. Três especialistas em natação competitiva, com formação acadêmica, analisaram o conteúdo e participaram da determinação das correlações intra e inter avaliadores. O conteúdo da lista apresentou clareza satisfatória (100\% fácil de entender), pertinência técnica também satisfatória (100\% muito adequado) e boa aplicabilidade (33\% muito viável e 66,7\% viável). Quanto à consistência e reprodutibilidade, pode-se inferir que a lista de checagem é adequada em virtude de a correlação intra-avaliador ter ficado entre 0,873 e 1.0 sendo que $91 \%$ das correlações estiveram acima de 0.9. Já a correlação inter-avaliador ficou entre 0.750 e 0.994 com $90 \%$ das correlações mantendo-se acima de 0.9 .

Para a classificação do grau de significância dos erros foi proposto que cinco técnicos de natação inicialmente respondessem a uma questão fechada sobre a magnitude da importância dos arrastos passivos e ativos no nado crawl. O primeiro equivale a todo o tipo de resistência que impede o deslocamento do nadador, já o segundo a ação de propulsão. $100 \%$ dos entrevistados identificaram o arrasto passivo como o fator de maior importância negativa para o deslocamento. Em seguida foi utilizada a técnica de ponderação de pesos para cada erro (PEREIRA, 2001) sendo os erros caracterizados como de arrasto ativo tendo valores de 0,5 e 1,0 e os erros categorizados como de arrasto passivo tendo valores de 1,5 e 2,0. A seguir os 5 profissionais aplicaram os pesos referentes a cada erro e a moda serviu como peso referencial final para cada erro. A partir dos resultados, conclui-se que a lista de checagem proposta é um instrumento válido para a avaliação qualitativa do nado crawl. E, portanto, foi o instrumento adotado para efetuar a análise qualitativa neste estudo.

\subsubsection{Carro de filmagem dinâmica aquática}

Para o desenvolvimento do estudo houve a necessidade de construir um carro que pudesse transportar duas filmadoras que deveriam acompanhar perpendicularmente 0 nadador, captando imagens dentro e fora d'água. Em estudos pilotos foram testadas alternativas para a captação das imagens. Inicialmente foi elaborado e construído um carro de PVC com rodas de borracha. Entretanto alguns contratempos surgiram, dentre eles, oscilações verticais em função de irregularidades do terreno e de pequenos deslocamentos de trajetória, entretanto, este instrumento foi funcional nas velocidades lenta e natural, porém, quando a velocidade de deslocamento dos voluntários era máxima, o suporte da 
filmadora subaquática, que também era de PVC, cedia em função do aumento da resistência oferecida pela água, o que inviabilizava o enquadramento do nadador. Uma alternativa para resolver estes problemas foi a tentativa de captação das imagens subaquáticas com os voluntários fixos em um ponto. Para esta possibilidade, outro conjunto de estudos pilotos fora feito. As seguintes possibilidades foram testadas. a-) Tipo de material para fixação do nadador, entre outros foram utilizados cabos de uretano, aço e elásticos cirúrgicos; b-) Quantidade e local de fixação do cabo, que foram, borda superior da piscina com um ponto fixo. Nesta condição, foram testadas as alturas de 30 e 50 centímetros do espelho de água. Outras alternativas testadas, foram o nadador permanecer fixo a dois cabos que ficavam presos as raias laterais da piscina e a possibilidade de dois pontos fixos que seriam as canoplas (local fixo à parede na altura do espelho de água, onde são presas as raias) e c-) Local e posicionamento de fixação do cabo no avaliado. Nesse sentido foram testados cabos presos aos pés e cintura, com sua extremidade voltada para cima, para baixo e laterais. Entretanto, para todas as alternativas observamos que características importantes do nado, como rotação do tronco, flutuação do quadril, comprimento das braçadas e freqüência de pernadas eram influenciadas pelos materiais, 0 que descaracterizava o padrão de nado natural do indivíduo. Tendo em vista as limitações apresentadas, tornou-se necessária a construção de um carro, posteriormente denominado carro de filmagem aquática dinâmica (CFAD), ver ilustração no ANEXO III. O CFAD foi construído com base de ferro e tubos de metalon, que corre sobre um trilho, para mais detalhes ver ANEXO IV. Com a construção deste equipamento, foi possível a análise aérea e submersa do comportamento do nado dos voluntários nas diferentes velocidades, sem os problemas mencionados.

\subsubsection{Filmadoras}

O registro dos dados foi feito por três filmadoras, duas da marca Sony Digital Handy Câmera Recorder, modelo TRV 340 (C1 e C2) e uma terceira câmera (C3) da marca LG, modelo LC-300 que captava as imagens subaquáticas que eram enviadas diretamente para o computador e gravadas pelo programa WIN DVD CREATOR. A C1 e a C3 estavam fixas ao CFAD, que era deslocado manualmente sobre um trilho preso à lateral da piscina. Elas estavam alinhadas verticalmente, uma na superfície e a segunda submersa e tinham como função captar as imagens que foram utilizadas como referência na análise qualitativa 
do nado. A C2 estava fixa a 6 metros de altura na cabeceira da piscina de frente ao ponto de início do experimento. Esta câmera captou as imagens que foram utilizadas para a análise temporal das braçadas.

\subsubsection{Marcação dos Pontos Anatômicos}

A tinta utilizada para marcar as crianças é composta por um material específico para maquiagem, não tóxica, da marca YUR, cores branca e preta. A marcação teve como objetivo facilitar a visualização do movimento dos segmentos das crianças pelos avaliadores, na fase subaquática. Os pontos marcados foram: Membros superiores - a) Mão - 50 metacarpo; b) Ante-braço - cabeça da ulna ou epicôndilo lateral e c) Braço - tubérculo maior do úmero.

\subsubsection{Software}

O software APAS 2000 (Ariel System) foi utilizado para a obtenção dos tempos de cada fase da braçada mediante a contagem do número de quadros.

\subsection{Medidas}

Foram utilizadas as seguintes medidas:

a-) Antropométricas: massa corporal, estatura, índice de massa corpórea, envergadura, somatória de dobras cutâneas e o percentual de gordura corporal.

Estas variáveis tinham como função, analisar a existência ou não da influência das mesmas, sobre os resultados, quando comparados os grupos experimentais.

b-) Desempenho: tempo total para nadar a distância de 30 metros, velocidade média para completar o percurso, freqüência de braçadas e comprimento médio das braçadas.

Estes dados foram usados para analisar o desempenho geral do nado, desenvolvido pelos grupos frente às tarefas.

c-) Aspectos invariantes: distribuição e variabilidade do timing relativo das fases aquática e aérea do braço direito e esquerdo. 
Para calcular estas variáveis, tivemos que decompor a braçada em duas fases: aquática e aérea. A duração total da braçada foi caracterizada como a somatória das fases aérea e aquática (tempo absoluto). Desta forma, com a duração total da braçada e as durações de cada fase foi possível calcular o timing relativo das mesmas, variável esta que consiste na porcentagem do tempo total de movimento (duração total da braçada) gasto em cada fase.

Estas medidas tiveram como finalidade permitir a análise da consistência no padrão temporal das braçadas, bem como, a variabilidade desta consistência.

d-) Aspectos variantes: distribuição e variabilidade do tempo total do ciclo de braçadas, do tempo absoluto da braçada e do tempo das fases aquática e aérea, para o braço direito e esquerdo.

O tempo total do ciclo de braçadas é resultante da somatória do tempo necessário para realizar uma braçada com cada braço (direito e esquerdo). O tempo absoluto da braçada é a soma do tempo para executar as fases aquática e aérea. $E$ o tempo da fase aquática foi determinado pela entrada do punho na água até a saída do mesmo, já a fase aérea, foi determinada pala saída do punho da água até sua entrada novamente na água.

Estas medidas permitiram a análise da parametrização do comportamento (flexibilidade) e a variabilidade da parametrização, isto é, a reprodutibilidade da mesma.

Para efeito de análise foram considerados três ciclos de braçadas consecutivos realizados na etapa intermediária do deslocamento. Isso foi determinado para evitar o efeito que a saída para o nado e a sua finalização, poderiam exercer sobre a organização temporal da braçada.

\subsection{Delineamento}

No presente estudo não foram adotados tratamentos diferenciados para os participantes, sendo assim, as instruções foram semelhantes, para os envolvidos no experimento. Todos executaram a tarefa, em três velocidades que foram a natural, rápida e lenta.

Cada criança foi testada individualmente e a seqüência das velocidades de deslocamento foi aleatória, determinada por sorteio. O intervalo de descanso entre cada uma das tarefas foi de no mínimo cinco minutos. 


\subsection{Procedimentos}

Inicialmente pais e filhos foram conduzidos para reconhecimento do local, isto é, sala de avaliação física, banheiros e piscinas. Em seguida, todos foram direcionados a uma sala onde foram descritas as etapas do experimento, que foram: 1-) avaliação antropométrica, 2) marcação de seis pontos anatômicos; 3-) familiarização da piscina e da tarefa e 4-) realização da tarefa para a análise.

\subsubsection{Procedimentos de coleta}

Nos estudos pilotos foram observados terminologias distintas usadas pelos professores, para definir os níveis de velocidade para o deslocamento. Com o intuito de dirimir este tipo de erro de interpretação, foram utilizadas as terminologias comuns na relação específica professor-criança.

Para a realização da tarefa a criança foi conduzida pelo experimentador até o local reservado para a mesma, o qual não deveria favorecer a visão dos demais indivíduos que estavam na espera. A seguir, o experimentador explicou a tarefa. Após a criança confirmar que compreendeu as instruções, o experimentador, dava início ao experimento.

\subsubsection{Procedimentos para constituição dos grupos}

Com o objetivo de constituir dois grupos em nível de habilidade distintos os participantes foram avaliados nadando em velocidade natural, por três especialistas mediante a lista de proficiência do nado crawl (ver ANEXO II). Como neste trabalho os avaliadores eram outros, isto é, os especialistas neste experimento, não foram os que validaram o instrumento de análise do nível de proficiência do nado crawl. Portanto, houve a necessidade de se reavaliar a confiabilidade do instrumento utilizado para definir os grupos do experimento. Para isto, seguiu-se o esquema apresentado por WEIR (2005). Primeiramente calculou-se um índice de confiabilidade relativo, o coeficiente de correlação 
intraclasse (CCl). Após estimar o CCl, fez-se uso de um estimador de confiança absoluto, representado pelo cálculo do erro típico da medida (ETM) e ETM percentual (ETM\%), seguindo as recomendações apontadas por HOPKINS (2000).

Devido aos diferentes modelos de $\mathrm{CCl}$, existe necessidade de definir aquele que responda aos objetivos da pesquisa. Desta forma, seguindo os conceitos apresentados por WEIR (2005) os modelos de CCI que seriam aplicáveis no presente estudo, diferem quanto a considerar ou não uma fonte de variância sistemática. Neste caso, o modelo de CCI 2, considera a fonte de variação ou erro sistemático, enquanto que o modelo de CCI 3 não leva em conta tal fonte de variação em seu cálculo.

Por sua vez, o ETM foi derivado a partir da média dos quadrados dos resíduos, uma das fontes de variação consideradas na análise de variância para medidas repetidas. $O$ ETM\% foi derivado da mesma fonte, entretanto, neste caso, os dados originais foram transformados em log natural e a medida de interesse foi re-transformada por meio do cálculo de exponenciação, o que derivou o ETM\% (HOPKINS, 2000).

TABELA 4 - Apresentação da significância da diferença entre avaliadores, coeficiente de correlação intraclasse e erro típico da medida.

\begin{tabular}{lccccc}
\hline & P AVAL $_{\text {A }}$ & C CI 2,1 & CCI 3,1 & ETM & ETM\% \\
\hline E.SOMA & 0,0000 & 0,7173318 & 0,9307786 & 3,2205590 & 13,211170 \\
\hline
\end{tabular}

E.SOMA: soma dos erros ponderados. $P_{\text {aval: }}$ significância do termo entre avaliadores. CCl: coeficiente de correlação intraclasse. ETM = erro típico da medida. ETM\% = erro típico percentual da medida.

A partir dos dados apresentados na TABELA 1, mostrou-se provável a existência da alteração sistemática da soma dos erros ponderados, sugerindo que os avaliadores não classificaram os voluntários de maneira semelhante. Tal fato foi confirmado ao se comparar os valores do $\mathrm{CCl}_{2,1}$ e $\mathrm{CCl}_{3,1}$, caso a variabilidade entre avaliadores fosse pequena ambos CCls apresentariam valores semelhantes. Por fim, o ETM\% indica que é possível esperar $\sim 15 \%$ de diferença entre os escores anotados pelos diferentes avaliadores. $\mathrm{O} \mathbf{C C l}_{3,1}$ entretanto, indicou que o teste a ser utilizado para a formação dos grupos na pesquisa é confiável. A partir da observação do ETM\%, adotou-se uma diferença entre os quantis da distribuição empírica dos dados de 15\% para definição dos grupos, de tal forma que os alunos do grupo mais habilidoso deveriam apresentar valor para a soma dos escores ponderados entre 0 e $35 \%$ (quantis $[17,7 ; 25,9]$ ). Por sua vez, os alunos do grupo menos habilidoso apresentaram escores ponderados entre 50 e $85 \%$ (quantis [30,4; 46,8]). Desta 
forma, dois grupos de níveis de habilidades distintas contendo quinze crianças em cada um, foram formados. Portanto, as outras crianças foram descartadas da amostra.

\section{RESULTADOS}

Conforme indicado por MENEZES (2004), inicialmente realizou-se a análise exploratória dos dados, com o objetivo de verificar se as observações apresentavam distribuição normal ou próxima da normal, para tal foram utilizadas a prova estatística de Shapro-Wilk e a inspeção dos gráficos de quantis (qq-plot). Além da normalidade, examinou-se as observações quanto à variabilidade, uma vez que supõe-se que os dados apresentem variabilidade semelhante entre os grupos ou situações (homocedasticidade), para tal foram empregados a prova estatística de Bartlet e as inspeção dos gráficos de stripchart, de acordo com as recomendações de DELGAARD (2002). As observações nas diversas variáveis seguiam ou podiam ser aproximadas pela distribuição normal e para a inferência estatística, optou-se por definir a significância estatística em á $\quad$ 0,05.

\subsection{Características Antropométricas}

Para averiguar a significância da diferença entre os grupos para as variáveis: idade, massa corporal, estatura, índice de massa corporal (IMC), envergadura, somatório de dobras cutâneas (SDC) e percentual de gordura (PGC), empregou-se o teste t de Student para amostras independentes. 
TABELA 5 - Descrição das características antropométricas dos grupos mais e menos habilidosos.

\begin{tabular}{lccc}
\hline \multicolumn{1}{c}{ Variável } & Mais habilidosos & Menos habilidosos & Diferença \\
\hline Idade (anos) & $9,3(1,1)$ & $8,6(1,5)$ & $0,7[-0,2 ; 1,7]$ \\
Massa corporal (kg) & $36,09(4,38)$ & $37,72(12,58)$ & $-1,63[-8,88 ; 5,61]$ \\
Estatura (m) & $1,42(0,09)$ & $1,36(0,13)$ & $0,06[-0,02 ; 0,15]$ \\
IMC (kg xm ${ }^{-2}$ ) & $17,80(2,22)$ & $19,71(3,62)$ & $-1,92[-4,19 ; 0,35]$ \\
Envergadura (cm) & $142,6(8,4)$ & $137,3(14,2)$ & $5,3[-3,5 ; 14,2]$ \\
SDC (mm) & $30,27(7,82)$ & $31,33(13,34)$ & $-1,07[-9,34 ; 7,20]$ \\
PGC (\%) & $25,95(4,96)$ & $26,88(9,84)$ & $-0,93[-6,86 ; 4,99]$ \\
\hline
\end{tabular}

Os dados para os grupos são apresentados na forma de média (desvio padrão).

Os dados para a diferença entre grupos são apresentados na forma de média [intervalo de confiança a 95\%].

Conforme indicado na TABELA 2, não foram evidenciadas diferenças estatisticamente significante entre as variáveis antropométricas para os grupos Mais $(+\mathrm{H})$ e Menos $(-\mathrm{H})$ habilidosos. Sendo assim, tais variáveis não têm poder para diferenciar os grupos neste experimento, quanto ao comportamento do nado frente as tarefas propostas.

\subsection{Características do desempenho}

Para verificar a significância da diferença entre grupos, entre condições de nado, bem como, a interação destes dois fatores nas variáveis: tempo para percorrer a distância de $30 \mathrm{~m}$; velocidade empregada; freqüência de braçadas e comprimento de braçada, utilizou-se a análise de variância a dois fatores mistos. 
TABELA 6 - Descrição das características do rendimento de nado.

\begin{tabular}{|c|c|c|c|}
\hline \multirow{2}{*}{ Variável } & \multicolumn{3}{|c|}{ Nado } \\
\hline & Lento & Natural & Máximo \\
\hline \multicolumn{4}{|l|}{ Tempo N30 (s) } \\
\hline Mais habilidosos ${ }^{c}$ & $36,40(3,85)$ & $35,20(5,19)^{a}$ & $31,13(3,27)^{a, b}$ \\
\hline $\begin{array}{l}\text { Menos } \\
\text { habilidosos }\end{array}$ & $48,73(9,65)$ & $44,40(7,25)^{a}$ & $42,67(8,35)^{a, b}$ \\
\hline Diferença & $\begin{array}{c}-12,33 \\
{[-17,95 ;-6,72]}\end{array}$ & $\begin{array}{c}-9,20 \\
{[-13,94 ;-4,46]}\end{array}$ & $\begin{array}{c}-11,53 \\
{[-16,39 ;-6,67]}\end{array}$ \\
\hline \multicolumn{4}{|c|}{ Velocidade média $\left(\mathrm{m} \times \mathrm{s}^{-1}\right)$} \\
\hline Mais habilidosos ${ }^{c}$ & $0,83(0,09)$ & $0,87(0,13)^{a}$ & $0,97(0,10)^{a, b}$ \\
\hline $\begin{array}{l}\text { Menos } \\
\text { habilidosos }\end{array}$ & $0,64(0,14)$ & $0,69(0,13)^{\mathrm{a}}$ & $0,73(0,15)^{a, b}$ \\
\hline Diferença & $0,18[0,10 ; 0,29]$ & $0,18[0,08 ; 0,27]$ & $0,24[0,15 ; 0,34]$ \\
\hline \multicolumn{4}{|c|}{ Freqüência de braçadas } \\
\hline Mais habilidosos & $30,5(6,6)$ & $31,7(7,0)$ & $35,1(7,0)$ \\
\hline $\begin{array}{l}\text { Menos } \\
\text { habilidosos }\end{array}$ & $28,3(12,0)$ & $28,5(11,6)$ & $32,4(15,2)$ \\
\hline Diferença & $2,2[-5,1 ; 9,5]$ & $3,2[-4,0 ; 10,4]$ & $2,7[-6,4 ; 11,7]$ \\
\hline \multicolumn{4}{|c|}{ Comprimento médio das braçadas $(\mathrm{m})$} \\
\hline Mais habilidosos & $1,04(0,30)$ & $1,06(0,30)$ & $0,89(0,22)$ \\
\hline $\begin{array}{l}\text { Menos } \\
\text { habilidosos }\end{array}$ & $1,24(0,51)$ & $1,21(0,45)$ & $1,14(0,59)$ \\
\hline Diferença & $-0,20[-0,52 ; 0,12]$ & $-0,20[-0,49 ; 0,08]$ & $-0,25[-0,59 ; 0,09]$ \\
\hline
\end{tabular}

Os dados para os grupos são apresentados na forma de média (desvio padrão).

Os dados para diferença entre os grupos são apresentados na forma de média [intervalo de confiança a $95 \%]$.

a indica diferença estatisticamente significante; $P \quad 0,05$; em relação à situação de nado lento.

${ }^{\mathrm{b}}$ indica diferença estatisticamente significante; $\mathrm{P} \quad 0,05$; em relação à situação de nado natural.

${ }^{c}$ indica diferença estatisticamente significante; $\mathrm{P} \quad$ 0,05; em relação ao grupo Menos Habilidoso, independentemente da situação de nado.

Na TABELA 3, podemos observar o comportamento do tempo de nado em 30metros (TN30), a velocidade média (VM), a freqüência de braçada (Fb) e o comprimento médio das braçadas ( $\mathrm{CMb})$, ou seja, as variáveis que respondem ao desempenho. Como se pode notar, foram encontradas diferenças estatisticamente significantes entre o grupo mais habilidoso $(+\mathrm{H})$ e menos habilidoso $(-\mathrm{H})$, para as variáveis TN30 e VM, (diferenciação da qualidade do nado) independente da situação de nado avaliada, que foram, nado lento (nl), nado natual $(\mathrm{nn})$ e nado máximo $(\mathrm{nm})$. Ainda com relação ao desempenho foram observadas diferenças estatisticamente significantes entre as situações de $\mathrm{nl}, \mathrm{nn}$ e nm para 
as variáveis TN30 e VM, independentemente do grupo considerado na análise. Sendo assim, podemos afirmar que os grupos se ajustaram as condições experimentais. Quanto ao comportamento das variáveis $\mathrm{Fb}$ e $\mathrm{CMb}$ não foram encontradas diferenças estatisticamente significantes nem para as velocidades e nem entre os grupos. Contudo, observando os valores médios, ambos os grupos, tenderam a aumentar a freqüência das braçadas e diminuir o comprimento com a alteração da velocidade lenta para a máxima, com o grupo $+\mathrm{H}$ apresentando uma maior freqüência de braçadas e menor comprimento das mesmas quando comparado com o outro grupo.

\subsection{Aspectos invariantes e variantes do nado}

Para verificar se o nível de habilidade (mais ou menos habilidosos) e a situação de nado (lento, natural ou máximo) poderiam influenciar as características invariantes (percentual das fases área e aquática) e variantes (duração da fase aérea e aquática da braçada; duração da braçada para ambos os braços e duração total do ciclo), utilizou-se a análise de variância a dois fatores mistos. Além de verificar diferenças entre o comportamento médio das características invariantes e variantes, calculou-se o ETM (HOPKINS, 2000) destas variáveis, avaliadas ao longo de três ciclos de braçadas, com o intuito de verificar a reprodutibilidade ou constância nos padrões de nado entre os grupos e velocidades. A partir das medidas de erro típico utilizou-se o teste $\mathrm{F}$ para verificar a significância da diferença entre duas estimativas de variâncias. A significância estatística foi estabelecida em á $\quad 0,05$. Por sua vez, o coeficiente de confiança, utilizado para indicar a incerteza quanto às estimativas pontuais, foi definido em $95 \%$.

\subsubsection{Aspectos invariantes}

Os aspectos invariantes, que neste estudo, foram identificados como os percentuais de tempo (timing relativo) na fase aérea e aquática das braçadas; correspondem à padronização temporal do movimento, ou seja, a consistência do comportamento do nadador. Portanto, indivíduos menos habilidosos, isto é, com a habilidade do nadar crawl, 
ainda não estabilizada, não deveriam manter uma padronização temporal entre as fases aérea e aquática da braçada.

A TABELA 4 apresenta os resultados do timing relativo das fases aérea e aquática dos braços direito e esquerdo, onde não foi encontrada diferença nas proporções da braçada nem entre as velocidades e nem entre os grupos. O que sugere, que os indivíduos apesar de serem de grupos de habilidades distintos, os mesmos já possuíam a habilidade estabilizada, portanto, conseguiram manter o padrão de nado, frente às modificações da tarefa. As FIGURAS 1 e 2 (ANEXO V), bem como, as FIGURAS 3 e 4 (ANEXO VI) ilustram os resultados.

TABELA 4 - Descrição do comportamento dos aspectos invariantes das braçadas de ambos os braços, para os grupos mais e menos habilidosos.

\begin{tabular}{|c|c|c|c|}
\hline \multirow{2}{*}{ Variável } & \multicolumn{3}{|c|}{ Nado } \\
\hline & Lento & Natural & Máximo \\
\hline \multicolumn{4}{|c|}{ Porcentagem da fase área do braço direito } \\
\hline Mais habilidosos & $21,2(4,4)$ & $22,4(5,4)$ & $21,4(3,1)$ \\
\hline $\begin{array}{l}\text { Menos } \\
\text { habilidosos }\end{array}$ & $21,3(7,1)$ & $23,4(5,7)$ & $22,2(5,5)$ \\
\hline \multicolumn{4}{|c|}{ Porcentagem da fase aquática do braço direito } \\
\hline Mais habilidosos & $78,8(4,4)$ & $77,6(5,4)$ & $78,6(3,1)$ \\
\hline $\begin{array}{l}\text { Menos } \\
\text { habilidosos }\end{array}$ & $78,7(7,1)$ & $76,7(5,7)$ & $77,8(5,5)$ \\
\hline \multicolumn{4}{|c|}{ Porcentagem da fase área do braço esquerdo } \\
\hline Mais habilidosos & $19,4(4,0)$ & $19,9(2,7)$ & $21,3(3,2)$ \\
\hline $\begin{array}{l}\text { Menos } \\
\text { habilidosos }\end{array}$ & $20,9(6,2)$ & $22,7(5,4)$ & $22,0(8,9)$ \\
\hline \multicolumn{4}{|c|}{ Porcentagem da fase aquática do braço esquerdo } \\
\hline Mais habilidosos & $80,6(4,0)$ & $80,1(2,7)$ & $78,7(3,2)$ \\
\hline $\begin{array}{l}\text { Menos } \\
\text { habilidosos }\end{array}$ & $79,1(6,2)$ & $77,3(5,4)$ & $78,0(8,9)$ \\
\hline
\end{tabular}

Os dados são descritos na forma de média (desvio padrão).

$\mathrm{Na}$ TABELA 5, não são evidenciadas diferenças significantes na constância do padrão de nado para as características invariantes, que foram o timing relativo da fase aérea e aquática de ambos os braços. Desta maneira, não foram encontradas diferenças entre os grupos ou situações de nado ao se considerar as proporções do tempo em relação 
à braçada total. As FIGURAS 5 e 6 (ANEXO VII) e as FIGURAS 7 e 8 (ANEXO VIII) ilustram os resultados.

TABELA 5 - Descrição da variabilidade observada nos aspectos invariantes em três ciclos de braçadas, para ambos os braços, nos grupos mais e menos habilidosos.

\begin{tabular}{|c|c|c|c|}
\hline \multirow{2}{*}{ Variável } & \multicolumn{3}{|c|}{ Nado } \\
\hline & Lento & Natural & Máximo \\
\hline \multicolumn{4}{|c|}{ Porcentagem da fase área do braço direito } \\
\hline Mais habilidosos & $4,39[3,21 ; 6,92]$ & $2,72[1,99 ; 4,29]$ & $2,16[1,58 ; 3,41]$ \\
\hline $\begin{array}{l}\text { Menos } \\
\text { habilidosos }\end{array}$ & $3,72[2,72 ; 5,87]$ & $5,33[3,9 ; 8,41]$ & $3,86[2,83 ; 6,09]$ \\
\hline P-valor & 0,7840 & 0,2205 & 0,2893 \\
\hline \multicolumn{4}{|c|}{ Porcentagem da fase aquática do braço direito } \\
\hline Mais habilidosos & $4,39[3,21 ; 6,92]$ & $2,72[1,99 ; 4,29]$ & $2,16[1,58 ; 3,41]$ \\
\hline $\begin{array}{l}\text { Menos } \\
\text { habilidosos }\end{array}$ & $3,72[2,72 ; 5,87]$ & $5,37[3,93 ; 8,47]$ & $3,86[2,83 ; 6,09]$ \\
\hline P-valor & 0,7840 & 0,2155 & 0,2893 \\
\hline \multicolumn{4}{|c|}{ Porcentagem da fase área do braço esquerdo } \\
\hline Mais habilidosos & $4,32[3,16 ; 6,81]$ & $2,35^{\star}[1,72 ; 3,71]$ & $2,38[1,74 ; 3,75]$ \\
\hline $\begin{array}{l}\text { Menos } \\
\text { habilidosos }\end{array}$ & $2,76[2,02 ; 4,35]$ & $6,99[5,12 ; 11,02]$ & $5,8[4,25 ; 9,15]$ \\
\hline P-valor & 0,7840 & 0,0503 & 0,1071 \\
\hline \multicolumn{4}{|c|}{ Porcentagem da fase aquática do braço esquerdo } \\
\hline Mais habilidosos & $4,32[3,16 ; 6,81]$ & $2,35^{\star}[1,72 ; 3,71]$ & $2,38[1,74 ; 3,75]$ \\
\hline $\begin{array}{l}\text { Menos } \\
\text { habilidosos }\end{array}$ & $2,76[2,02 ; 4,35]$ & $6,99[5,12 ; 11,02]$ & $5,8[4,25 ; 9,15]$ \\
\hline P-valor & 0,7840 & 0,0503 & 0,1071 \\
\hline
\end{tabular}

Os dados para ambos os grupos são apresentados na forma de erro típico da medida [intervalo de confiança a 95\%].

Os dados para $\mathrm{P}$-intergrupo representam a probabilidade de observar diferenças entre razões tão extremas quanto à calculada e que tenham origem pelo acaso.

\subsubsection{Aspectos variantes}


Os aspectos variantes, que neste estudo foram identificados como Tfarb, Tfaqb, TTb e tempo do ciclo total (TcT), de ambos os braços, correspondem à possibilidade de parametrização e, portanto, à possível flexibilidade do comportamento motor estabilizado.

TABELA 6 - Descrição do comportamento dos aspectos variantes do nado para o braço direito.

\begin{tabular}{|c|c|c|c|}
\hline \multirow{2}{*}{ Variável } & \multicolumn{3}{|c|}{ Nado } \\
\hline & Lento & Natural & Máximo \\
\hline \multicolumn{4}{|c|}{ Tempo da fase aérea do braço direito } \\
\hline Mais habilidosos & $372,9(103,0)$ & $381,2(106,4)$ & $301,4(71,0)^{a, b}$ \\
\hline $\begin{array}{l}\text { Menos } \\
\text { habilidosos }\end{array}$ & $504,1(142,0)$ & $494,0(141,8)$ & $354,7(85,0)^{a, b}$ \\
\hline \multicolumn{4}{|c|}{ Tempo da fase aquática do braço direito } \\
\hline Mais habilidosos & $1380,4(268,9)$ & $1325,7(254,7)^{\mathrm{c}}$ & $1100,3(183,6)^{d}$ \\
\hline $\begin{array}{l}\text { Menos } \\
\text { habilidosos }\end{array}$ & $2025,0(793,0)$ & $1661,1(401,6)$ & $1258,9(342,3)$ \\
\hline \multicolumn{4}{|c|}{ Tempo total da braçada do braço direito } \\
\hline Mais habilidosos & $1753,3(321,8)$ & $1707,0(286,5)$ & $1401,7(235,2)^{d}$ \\
\hline $\begin{array}{l}\text { Menos } \\
\text { habilidosos }\end{array}$ & $2529,0(891,3)$ & $2154,8(468,0)$ & $1613,6(385,6)$ \\
\hline \multicolumn{4}{|c|}{$\begin{array}{ll}\text { Os dados são descritos na forma de média } & \text { (desvio padrão). } \\
\text { a diferença estatisticamente significante; } P & 0,05 ; \text { em relação à situação de nado lento. } \\
\text { b diferença estatisticamente significante; } P & 0,05 ; \text { em relação à situação de nado natural. } \\
\text { c interação estatisticamente significante; P } & 0,05 ; \text { entre os grupos e o comportamento da passagem } \\
\text { do nado lento para nado natural. } & \end{array}$} \\
\hline
\end{tabular}

Conforme indicado na TABELA 6 o tempo da fase aérea do braço direito (Tfarbd) apresentou modificação entre as velocidades de nado para ambos os grupos, entretanto, não houve diferença estatística entre os grupos. Isto significa que conforme a velocidade de nado era aumentada ocorria uma diminuição do tempo de permanência da fase aérea do braço direito para os dois grupos e esta modificação, foi similar entre o grupo $+\mathrm{H}$ e $0-\mathrm{H}$. Para o tempo da fase aquática do braço direito (Tfaqbd) os dados mostraram que os grupos se comportaram de forma diferente, isto é, apesar de Tfaqbd ter se modificado nas diferentes velocidades para os grupos, esta modificação do comportamento do nado não foi similar, o grupo mais habilidoso acabou modificando menos seu tempo de permanência na 
fase aquática da braçada entre as velocidades lenta e máxima - 280 milisegundos (ms), quando comparado com o grupo menos habilidoso - $767 \mathrm{~ms}$ e o mesmo ocorreu entre as velocidades lenta e natural $-55 \mathrm{~ms}$ e $-364 \mathrm{~ms}$. Já para a variável tempo total da braçada do braço direito (TTbd) o grupo $+\mathrm{H}$ apresentou uma menor diferença temporal total entre as velocidades lenta e máxima do que o grupo $-\mathrm{H}$, respectivamente $-352 \mathrm{~ms}$ e $979 \mathrm{~ms}$. Frente a estes resultados podemos afirmar que os grupos se comportaram de forma diferente para as velocidades, Tfaqbd e TTbd, entretanto, o comportamento foi similar para Tfarbd. Os ANEXO IX e X, ilustram os resultados.

TABELA 7 - Descrição do comportamento das características variantes do nado para o braço esquerdo.

\begin{tabular}{|c|c|c|c|}
\hline \multirow{2}{*}{ Variável } & \multicolumn{3}{|c|}{ Nado } \\
\hline & Lento & Natural & Máximo \\
\hline \multicolumn{4}{|c|}{ Tempo da fase aérea do braço esquerdo } \\
\hline Mais habilidosos & $339,1(84,5)$ & $332,9(57,1)$ & $299,1(55,5)^{a, b}$ \\
\hline $\begin{array}{l}\text { Menos } \\
\text { habilidosos }\end{array}$ & $496,4(162,8)$ & $479,3(89,9)$ & $327,0(150,5)$ \\
\hline \multicolumn{4}{|c|}{ Tempo da fase aquática do braço esquerdo } \\
\hline Mais habilidosos & $1429,2(296,8)$ & $1359,3(246,5)$ & $1111,1(195,3)^{a, b}$ \\
\hline $\begin{array}{l}\text { Menos } \\
\text { habilidosos }\end{array}$ & $2017,0(774,0)$ & $1674,8(409,4)$ & $1220,1(374,8)$ \\
\hline \multicolumn{4}{|c|}{ Tempo da braçada do braço esquerdo } \\
\hline Mais habilidosos & $1768,2(327,0)$ & $1692,2(282,9)$ & $1401,2(228,6)^{a, b}$ \\
\hline $\begin{array}{l}\text { Menos } \\
\text { habilidosos }\end{array}$ & $2513,4(867,0)$ & $2154,2(447,8)$ & $1547,1(437,9)$ \\
\hline $\begin{array}{l}\text { Os dados são descritos } \\
\text { a interação estatisticame } \\
\text { do nado natural para nac } \\
\text { b interação estatisticame } \\
\text { do nado lento para nado }\end{array}$ & $\begin{array}{lr}\text { rma de média } & \text { (des } \\
\text { significante; } P & 0,0 \\
\text { áximo. } & \\
\text { significante; } P & 0,0 \\
\text { imo. } & \end{array}$ & $\begin{array}{l}\text { drão). } \\
\text { re os grupos e o co } \\
\text { e os grupos e o col }\end{array}$ & $\begin{array}{l}\text { tamento da passagem } \\
\text { amento da passagem }\end{array}$ \\
\hline
\end{tabular}


A TABELA 7 mostra que os grupos apresentaram comportamentos diferentes frente às velocidades, entretanto, também foi evidenciada diferença entre os grupos para todas as variáveis. No tempo da fase aérea do braço esquerdo (Tfarbe) para a passagem da velocidade lenta para a velocidade máxima o grupo mais habilidoso apresentou uma diminuição de $100 \mathrm{ml} / \mathrm{s}$, enquanto que o grupo menos habilidoso apresentou uma diminuição $169 \mathrm{ml} / \mathrm{s}$. Já para o tempo da fase aquática do braço esquerdo (Tfaqbe) entre as velocidades lenta e máxima encontramos uma diminuição de $318 \mathrm{ml} / \mathrm{s}$ e $797 \mathrm{ml} / \mathrm{s}$ para os $+\mathrm{H}$ e $-\mathrm{H}$, respectivamente. Para o tempo total da braçada esquerda entre as velocidades lenta e máxima o grupo $+\mathrm{H}$ diminuiu seu tempo de total em $358 \mathrm{ml} / \mathrm{s}$ já o grupo $-\mathrm{H}$ apresentou uma diminuição de 966 ml/s. As FIGURAS 12 e 13 (ANEXO XI) e a FIGURA 14 (ANEXO XII) demonstram o ocorrido.

TABELA 8 - Descrição do comportamento das características variantes do nado para o ciclo total.

\begin{tabular}{|c|c|c|c|}
\hline \multirow{2}{*}{ Variável } & \multicolumn{3}{|c|}{ Nado } \\
\hline & Lento & Natural & Máximo \\
\hline \multicolumn{4}{|c|}{ Tempo do ciclo total } \\
\hline Mais habilidosos & $3521,5(647,8)$ & $3399,2(567,3)$ & $2811,8(463,5)^{a, b}$ \\
\hline $\begin{array}{l}\text { Menos } \\
\text { habilidosos }\end{array}$ & $5042,4(1757,4)$ & $4309,0(908,9)$ & $3160,7(801,4)$ \\
\hline \multicolumn{4}{|c|}{ 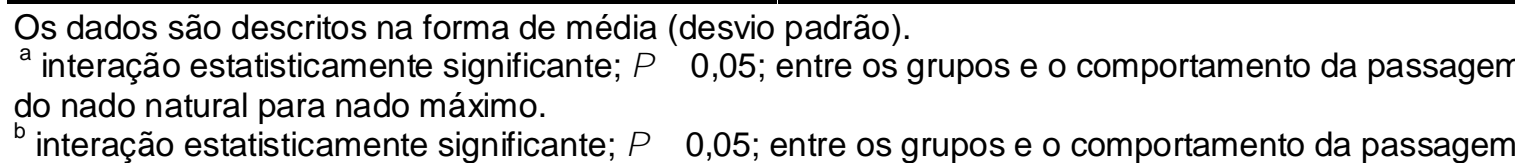 } \\
\hline
\end{tabular}

$\mathrm{Na}$ TABELA 8 os dados indicam que houve diferença estatisticamente significante de comportamento para os grupos frente à modificação da velocidade, bem como houve diferença entre os grupos para o tempo do ciclo total (TcT), desta forma, entre a velocidade de nado natural para o nado máximo e do nado lento para o máximo, as alterações temporais foram: -588 e $-710 \mathrm{ml} / \mathrm{s}$ para o grupo mais habilidoso e -1149 e $-1882 \mathrm{ml} / \mathrm{s}$ para o grupo menos habilidoso. Estes dados também podem ser conferidos na FIGURA 15 (ANEXO XIII)

Os resultados contidos nas tabelas 9, 10 e 11 para as variáveis: tempo da fase aérea e aquática do braço direito, tempo total da braçada direita; tempo da fase aérea e aquática do braço esquerdo, tempo total da braçada da esquerda e o tempo do ciclo total indicam 
que o grupo $+\mathrm{H}$ é significativamente mais reprodutível ou constante, que seus colegas do grupo $-\mathrm{H}$.

Na TABELA 9 ainda podemos observar que a variabilidade de Tfabd, Tfaqbd e TTbd para o grupo $+\mathrm{H}$, foi diminuindo com o aumento da velocidade, o mesmo não ocorreu com o grupo $-\mathrm{H}$, que apresentou maior variabilidade na velocidade de nado natural para as três variáveis analisadas. As ilustrações contidas nos ANEXOS XIV e XV auxiliam na observação dos resultados.

TABELA 9 - Descrição da variabilidade observada nas características variantes em três braçadas para o braço direito.

\begin{tabular}{|c|c|c|c|}
\hline \multirow{2}{*}{ Variável } & \multicolumn{3}{|c|}{ Nado } \\
\hline & Lento & Natural & Máximo \\
\hline \multicolumn{4}{|c|}{ Tempo da fase aérea do braço direito } \\
\hline Mais habilidosos & $\begin{array}{c}95,88 \\
{[70,2 ; 151,21]}\end{array}$ & $\begin{array}{c}74,31 \\
{[54,4 ; 117,19]}\end{array}$ & $\begin{array}{c}40,72^{*} \\
{[29,81 ; 64,22]}\end{array}$ \\
\hline Menos habilidosos & $\begin{array}{c}111,31 \\
{[81,49 ; 175,55]}\end{array}$ & $\begin{array}{c}161,81 \\
{[118,47 ; 255,19]}\end{array}$ & $\begin{array}{c}121,17 \\
{[88,71 ; 191,1]}\end{array}$ \\
\hline P-valor & 0,7840 & 0,1577 & 0,0502 \\
\hline \multicolumn{4}{|c|}{ Tempo da fase aquática do braço direito } \\
\hline Mais habilidosos & $\begin{array}{c}91,79 \\
{[67,2 ; 144,76]}\end{array}$ & $\begin{array}{c}58,23^{*} \\
{[42,63 ; 91,83]}\end{array}$ & $\begin{array}{c}44,78^{*} \\
{[32,78 ; 70,62]}\end{array}$ \\
\hline Menos habilidosos & $\begin{array}{c}192,21 \\
{[140,72 ; 303,13]}\end{array}$ & $\begin{array}{c}252,65 \\
{[184,97 ; 398,45]}\end{array}$ & $\begin{array}{c}147,2 \\
{[107,77 ; 232,15]}\end{array}$ \\
\hline P-valor & 0,1791 & 0,0096 & 0,0333 \\
\hline \multicolumn{4}{|c|}{ Tempo da braçada do braço direito } \\
\hline Mais habilidosos & $\begin{array}{c}109,06 \\
{[79,85 ; 172]}\end{array}$ & $\begin{array}{c}106,93^{*} \\
{[78,29 ; 168,64]}\end{array}$ & $\begin{array}{c}56,37^{*} \\
{[41,27 ; 88,9]}\end{array}$ \\
\hline Menos habilidosos & $\begin{array}{c}216,06 \\
{[158,18 ; 340,75]}\end{array}$ & $\begin{array}{c}321,69 \\
{[235,52 ; 507,34]}\end{array}$ & $\begin{array}{c}243,86 \\
{[178,54 ; 384,59]}\end{array}$ \\
\hline P-valor & 0,2132 & 0,0480 & 0,0097 \\
\hline
\end{tabular}

Os dados para ambos os grupos são apresentados na forma de erro típico da medida [intervalo de confiança a $95 \%]$.

Os dados para P-valor representam a probabilidade de observar diferenças entre razões tão extremas quanto à calculada e que tenham origem pelo acaso.

Na TABELA 10 pode se constatar a ocorrência na variabilidade observada com o braço direito, se repetindo com o braço esquerdo entre os grupos para as variáveis Tfabe, Tfaqbe e TTbe, portanto, o grupo mais habilidoso apresentou menor variabilidade com o aumento da velocidade, o que não ocorreu com o grupo menos habilidoso que apresentou 
maior variabilidade na velocidade de nado natural para as três variáveis analisadas. Ver ANEXOS XVI e XVII.

TABELA 10 - Descrição da variabilidade observada nas características variantes em três braçadas para o braço esquerdo.

\begin{tabular}{|c|c|c|c|}
\hline \multirow{2}{*}{ Variável } & \multicolumn{3}{|c|}{ Nado } \\
\hline & Lento & Natural & Máximo \\
\hline \multicolumn{4}{|c|}{ Tempo da fase aérea do braço esquerdo } \\
\hline Mais habilidosos & $\begin{array}{c}110,13 \\
{[80,63 ; 173,69]}\end{array}$ & $\begin{array}{c}37,03 \text { * } \\
{[27,11 ; 58,4]}\end{array}$ & $\begin{array}{c}28,72 \\
{[21,03 ; 45,29]}\end{array}$ \\
\hline Menos habilidosos & $\begin{array}{c}74,6 \\
{[54,62 ; 117,65]}\end{array}$ & $\begin{array}{c}180,46 \\
{[132,12 ; 284,6]}\end{array}$ & $\begin{array}{c}59,88 \\
{[43,84 ; 94,44]}\end{array}$ \\
\hline P-valor & 0,7840 & 0,0054 & 0,1816 \\
\hline \multicolumn{4}{|c|}{ Tempo da fase aquática do braço esquerdo } \\
\hline Mais habilidosos & $\begin{array}{c}131,79 \\
{[96,49 ; 207,85]}\end{array}$ & $\begin{array}{c}70,29 * \\
{[51,46 ; 110,85]}\end{array}$ & $\begin{array}{c}68,11 \\
{[49,87 ; 107,42]}\end{array}$ \\
\hline Menos habilidosos & $\begin{array}{c}241,45 \\
{[176,77 ; 380,79]}\end{array}$ & $\begin{array}{c}327,44 \\
{[239,73 ; 516,41]}\end{array}$ & $\begin{array}{c}173,28 \\
{[126,86 ; 273,28]}\end{array}$ \\
\hline P-valor & 0,2694 & 0,0068 & 0,0916 \\
\hline \multicolumn{4}{|c|}{ Tempo da braçada do braço esquerdo } \\
\hline Mais habilidosos & $\begin{array}{c}171,07 \\
{[125,24 ; 269,79]}\end{array}$ & $\begin{array}{c}63,54^{*} \\
{[46,52 ; 100,21]}\end{array}$ & $\begin{array}{c}60,25^{\star} \\
{[44,11 ; 95,02]}\end{array}$ \\
\hline Menos habilidosos & $\begin{array}{c}247,4 \\
{[181,13 ; 390,17]}\end{array}$ & $\begin{array}{c}397,8 \\
{[291,24 ; 627,37]}\end{array}$ & $\begin{array}{c}190,36 \\
{[139,37 ; 300,22]}\end{array}$ \\
\hline P-valor & 0,4990 & 0,0015 & 0,0393 \\
\hline
\end{tabular}

Os dados para ambos os grupos são apresentados na forma de erro típico da medida [intervalo de confiança a 95\%].

Os dados para $\mathrm{P}$-valor representam a probabilidade de observar diferenças entre razões tão extremas quanto à calculada e que tenham origem pelo acaso. 
Os resultados mostrados na TABELA 11 expressam as conseqüências mostradas nos dados anteriores o grupo $-\mathrm{H}$ apresenta maior variabilidade durante $\mathrm{o}$ nado em velocidade natural, enquanto que o grupo $+\mathrm{H}$ reduz sua variabilidade com o aumento da velocidade. Ver ANEXO XVIII.

TABELA11 - Descrição da variabilidade observada nas características variantes em três ciclos de braçadas totais.

\begin{tabular}{cccc}
\hline Variável & \multicolumn{3}{c}{ Nado } \\
\cline { 2 - 4 } & Lento & Natural & Máximo \\
\hline Tempo do ciclo total & & & \\
Mais habilidosos & 208,16 & $148,64^{\star}$ & 102,45 \\
& {$[152,4 ; 328,29]$} & {$[108,82 ; 234,42]$} & {$[75,01 ; 161,57]$} \\
Menos habilidosos & 348,87 & 496,24 & 262,85 \\
P-valor & {$[255,42 ; 550,2]$} & {$[363,31 ; 782,62]$} & {$[192,44 ; 414,54]$} \\
\hline
\end{tabular}

Os dados para ambos os grupos são apresentados na forma de erro típico da medida [intervalo de confiança a $95 \%]$.

Os dados para P-valor representam a probabilidade de observar diferenças entre razões tão extremas quanto à calculada e que tenham origem pelo acaso.

\section{DISCUSSÃO}

$\mathrm{Na}$ análise das medidas antropométricas (idade, massa corporal, estatura, índice de massa corpórea, envergadura, soma de dobras cutâneas e percentual de gordura corporal) não foram detectadas diferenças entre o grupo mais habilidodo $(+H)$ e o grupo menos habilidoso $(-H)$. Desta forma, os resultados obtidos nas demais medidas utilizadas neste estudo e apresentados a seguir não podem ser atribuídos as características antropométricas dos voluntários.

Em relação ao desempenho, ambos os grupos apresentaram tempo para nadar os 30 metros e velocidade média distintos, em cada uma das condições experimentais (nado lento, nado natural e nado máximo). Mas especificamente, o tempo de nado na condição lenta de ambos os grupos foi superior ao da condição de nado natural, e este último, foi superior ao do registrado para o nado em velocidade máxima. Ainda, o comportamento em relação à velocidade foi o inverso ao do tempo, ou seja, a velocidade de nado na condição nado lento de ambos os grupos foi inferior à da condição de nado natural, e esta, por sua 
vez, foi inferior a registrada para o nado em velocidade máxima. Esses resultados demonstram que, tanto o grupo $+\mathrm{H}$ como $0-\mathrm{H}$, diferenciaram o tempo e a velocidade de deslocamento e, que esta diferenciação, ocorreu conforme o solicitado pelo pesquisador.

Entretanto, para ambos os grupos não foram detectadas diferenças intragrupo, nas variáveis freqüência da braçada e comprimento da braçada entre as condições experimentais. Portanto, a rigor, a alteração das velocidades não ocorreu em função destas variáveis. Estes resultados não corroboram com os apresentados por SEIFERT, BOULESTEIX e CHOLLET (2004) e SEIFERT et alii (2005). Mas, observando os valores médios de $+\mathrm{H}$ e $-\mathrm{H}$ pode-se verificar que entre a situação de nado lento e a de nado máximo há uma tendência de aumento de freqüência da braçada $e$, inversamente, de diminuição do comprimento da mesma. Em suma, estes resultados mostraram que houve modificação do desempenho de ambos os grupos em função das modificações da tarefa (nados lento, natural e máximo)

Por sua vez, na comparação entre os grupos foi detectada diferença no tempo e velocidade do nado. Em cada uma das condições, em comparação com o grupo - H, o grupo $+\mathrm{H}$ precisou de menos tempo para completar os 30 metros e o fez em velocidade maior. Assim, como o esperado, o desempenho dos $+\mathrm{H}$, foi superior ao dos $-\mathrm{H}$. Desta forma, os grupos constituídos em função dos comportamentos espaciais do nado apresentaram diferença quanto ao desempenho, especificamente, o grupo classificado como o mais habilidosos também foi o grupo que apresentou o melhor desempenho nas três condições experimentais. Em relação à freqüência e comprimento da braçada não foi detectada diferença entre os grupos.

Considerando os resultados das medidas antropométicas em conjunto com os resultados nas medidas de desempenho, especificamente, de tempo e velocidade de nado, pode-se inferir que as características antropométricas não possuem relação com 0 desempenho. Portanto, estes resultados não sustentam os encontrados na literatura relativos à atletas de alto nível (PLATONOV \& FESSENKO, 2004; GRIMSTON \& HAY, 1986). Assim, nestes níveis de habilidade do nado crawl, parece que as variáveis antropométricas não são determinantes para o desempenho.

Em relação aos aspectos invariantes da braçada, isto é, o timing relativo; não houve diferença estatística intragrupo, para a fase aquática e aérea, para ambos os grupos. Vale lembrar, que esta medida corresponde à organização temporal da braçada, ou seja, ao 
tempo gasto nas fases aérea e aquática em relação à braçada total. Portanto, estes resultados demonstram que, frente à mudança de velocidade de nado (desempenho) não foi efetuada alteração na organização temporal deste componente. A manutenção da estrutura temporal da braçada do nado crawl, ao longo de condições experimentais distintas, mostra que ambos os grupos apresentam um comportamento estabilizado e, principalmente, induz à idéia de existência de uma representação mental subjacente ao comportamento (SCHMIDT, 2003). Portanto, esses resultados reforçam a conclusão de FREUDENHEIM, et alii (2005) de que o nadar crawl requer uma representação cognitiva da ação.

Ainda em relação à organização temporal da braçada, não foram encontradas diferenças entre os grupos para nenhuma das condições experimentais. Portanto, embora os grupos possuam níveis de habilidades distintos, esta diferença não implica em efeitos diferenciados frente à modificação da tarefa em relação a distribuição temporal da braçada.Este resultado pode ser explicada, pois foram selecionadas crianças em níveis distintos do nado crawl mas com tempo de prática similares $3,86(0,83)$ anos para os $+\mathrm{H}$ e $3,66(0,81)$ anos para os $-\mathrm{H}$.

Considerando os resultados relacionados ao tempo e velocidade de nado, verifica-se que, embora o grupo $+\mathrm{H}$ tenha tido desempenho superior ao $-\mathrm{H}$ em todas as condições, que esta superioridade não se deve a ajustes na organização temporal da braçada.

Por sua vez, em relação à variabilidade do timing relativo das fases aérea e aquática foram detectadas diferenças estatísticas entre os grupos em relação à braçada esquerda e não em relação à braçada direita. Mais especificamente os mais habilidosos foram mais consistentes na fase aérea e aquática da braçada esquerda que os menos habilidosos. Esses resultados são semelhantes aos obtidos por FREUDENHEIM, et alli (2005) e podem ser explicados a partir da visão contínua do processo de aquisição de habilidades (TANI, 1995). Pois, uma criança em um nível mais avançado do nado crawl, passou por mais ciclos de estabilidade e quebra de estabilidade, que uma criança menos habilidosa, na mesma habilidade. É provável, portanto, que a organização temporal de seu nado seja mais estável, ou seja, que compreenda menor variabilidade nos aspectos invariantes da ação (por exemplo, timing relativo). Pode-se inferir que a estrutura mental subjacente ao comportamento dos indivíduos mais habilidosos é mais complexa que a dos indivíduos menos habilidosos. 
Em relação aos aspectos variantes da braçada do nado crawl, foram detectados efeitos significantes para o tempo da fase aérea e aquática dos braços direito e esquerdo, em ambos os grupos. Em relação à braçada direita, o tempo despendido nestas fases, na condição de nado máximo, foi inferior ao tempo despendido na fase aérea nas condições de nado natural e lento, para ambos os grupos. Assim, as alterações detectadas apresentaram uma relação inversa entre velocidade (nado lento e nado máximo) e o tempo gasto em cada uma das fases da braçada. Inclusive, em relação ao tempo do ciclo inteiro da braçada direita, foi detectada diferença entre as condições de nado lento e máximo, em ambos os grupos. Estes resultados mostram que em função da modificação da tarefa (do nado lento para o máximo), houve uma diminuição do ciclo da braçada do lado direito, em função de ambas as fases da braçada.

Em relação à braçada esquerda, foram identificadas diferenças em todas as condições experimentais, para ambos os grupos. As relações temporais foram inversamente proporcionais às velocidades de nado, isto é, quanto mais veloz os indivíduos de ambos os grupos se deslocavam menores os tempos de permanência nas fases da braçada.

Considerando os resultados das comparações intragrupo dos aspectos invariantes e variantes em conjunto, pode-se assumir que as alterações de desempenho em função da condição experimental foram efetuadas, por ambos os grupos, a partir de ajustes dos aspectos variantes das braçadas. Portanto, ao longo das três condições a manutenção da organização temporal da braçada garantiu sua consistência e as alterações do parâmetro tempo asseguraram a capacidade do indivíduo de se ajustar às demandas específicas da tarefa, ou seja, garantiram sua flexibilidade. Segundo TANI (1995), frente à modificação da tarefa, quando as alterações no desempenho ocorrem por meio da própria flexibilidade do sistema, isto é, via ajustes dos aspectos variantes, pode-se considerar que houve adaptação passiva.

$\mathrm{Na}$ comparação entre grupos, não foi evidenciada diferença para Tfarbd, nas três condições. Já em Tfaqbd houve interação entre grupos e condições de nado lento para o máximo e do natural para o máximo. Por sua vez, o tempo total da braçada direita foi diferente entre os grupos na passagem da velocidade de nado lento para nado máximo. Estes resultados mostram que nas variáveis analisadas (Tfarbd, Tfaqbd e TTbd), o grupo $+\mathrm{H}$ foi mais rápido que o grupo $-\mathrm{H}$. Quanto a variabilidade, o grupo $+\mathrm{H}$ demonstrou ser mais consistente do que $-\mathrm{H}$, pois detectou-se diferença entre os grupos em relação as variáveis 
Tfaqbd e TTbd nas situações de nado natural e de nado máximo, bem como, em relação ao Tfarbd na condição de nado em velocidade máxima. Estes resultados sugerem que, em relação ao grupo $-\mathrm{H}$, os ajustes realizados pelo grupo $+\mathrm{H}$, foram de proporções menores nas diferentes condições. Assim em conjunto estes resultados sugerem que o grupo $-\mathrm{H}$ foi mais sensível às modificações da tarefa que o grupo $+\mathrm{H}$.

Já a braçada esquerda do grupo $+\mathrm{H}$ foi mais consistente que a do grupo $-\mathrm{H}$ em todas as medidas na condição de nado natural na medida de tempo total da braçada esquerda (Ttbe) na condição de nado em velocidade máxima. Estes resultados sugerem que, em comparação com as braçadas do grupo $-\mathrm{H}$, como na braçada direita, os ajustes efetuados pelo grupo $+\mathrm{H}$, foram de proporções menores nas diferentes condições. Esses resultados reforçam a inferência de que o grupo $-\mathrm{H}$ foi mais sensível às modificações do que o grupo $+\mathrm{H}$.

No tempo de ciclo total os resultados mostraram que ambos os grupos se comportaram de formas diferentes frente às condições experimentais ( $\mathrm{nl}, \mathrm{nn}$ e nm). Além disso, os grupos apresentaram respostas diferentes frente às condições experimentais, sendo grupo $+\mathrm{H}$ caracterizado pelo grupo que menores alterações temporais efetuou para as diferentes situações. Quanto à variabilidade, o grupo $+\mathrm{H}$ também foi mais consistente que o grupo $-\mathrm{H}$ o que foi evidenciado na velocidade natural.

Os resultados dos aspectos variantes da braçada demonstram, que apesar de o grupo $+\mathrm{H}$ apresentar maior consistência do nado do que o grupo $-\mathrm{H}$, ainda assim, foi detectada a existência de variabilidade no padrão da habilidade. Esta variabilidade demonstrou ser funcional (MANOEL \& CONNOLLY ,1995), para ambos os grupos, pois permitiu modificações no ciclo da braçada, sem que os indivíduos, tivessem que alterar seu padrão de nado.

\section{CONCLUSÃO}

O presente estudo investigou o efeito da modificação da tarefa na braçada do nado crawl em crianças, em níveis de habilidades distintos. Com base nos resultados, pode-se concluir que:

a-) Crianças que nadam crawl são capazes de ajustar seu desempenho em função de modificações da tarefa (nados lento, natural e máximo); 
b-) No nado crawl de crianças, há relação entre organização espacial e desempenho na tarefa, pois grupos constituídos em função dos comportamentos espaciais do nado apresentaram diferença correspondente quanto ao desempenho;

c-) Características antropométricas, nesta faixa etária e nível de habilidade, não interferem no desempenho;

d-) Os nadadores mantiveram a organização temporal da braçada do nado crawl ao longo das três condições experimentais que, no caso, corresponderam a desempenhos distintos e, portanto, infere-se que há uma estrutura mental subjacente ao nadar;

e-) Em relação ao grupo menos habilidoso, a organização temporal da braçada dos mais habilidosos, foi mais estável, indicando, desta forma, que as diferenças no nível de habilidade implicam em estruturas mentais em nível de complexidade distintos;

$\mathrm{f}$-) Ao longo das três condições, a manutenção da organização temporal da braçada garantiu sua consistência e as alterações do parâmetro tempo, asseguraram a capacidade do indivíduo de se ajustar às demandas específicas da tarefa, ou seja, garantiram sua flexibilidade;

g-) As alterações de desempenho em função das condições experimentais foram efetuadas, por ambos os grupos, exclusivamente a partir de ajustes dos aspectos variantes das braçadas, portanto, via adaptação passiva;

Em suma, em função do exposto, conclui-se que a aquisição do nadar vista como um processo contínuo, envolve a formação de estruturas mentais que asseguram tanto a consistência como a flexibilidade da braçada e, que sua complexidade está associada ao nível de habilidade dos nadadores.

\section{REFERÊNCIAS}

ADAMS, J. A. A closed-loop therory of motor learning. Journal of Motor Behavior, Washington, v.3, p.111-150, 1971.

ANJOS, M.; FERREIRA M.B.; GEISGER A; MEDEIROS E.P.; MARQUES J.C. Mini Aurélio, São Paulo: Nova Fronteira, 2000. 
BERTALANFFY, L. V. Teoria geral dos sistemas. Petrópolis: Vozes, 1977

BLANKSBY, B.A.; PARKER, H.E.; BRADLEY, S. Children's readiness for learning front crawl swimming. Australian Journal of Science and Medicine in Sport, Melbourne, v.27, n.2, p.34-37, 1995.

BROOKS, R. W.; LANCE, C. C.; SAWHILL, J. A. The biomechanical interaction of lift and propulsion forces during swimming. Medicine and Science in Sports and Exercise, Madison, v.32, n.5, p.910, 2000.

CARDELLI, C.; CHOLLET, D.; LERDA, R. Analysis of the 100-M front crawl as a function of skill level in non-expert swimmers. Journal of Human Movement Studies, London, v.36, p.51-74, 1999.

CHOLLET, D.; CHARLIES, S.; CHATARD, J.C. A new index of coordenation for the crawl: description and usefulness. International Journal Sports Medicine, Stuttgard, v.21, p. 54-9, 2000.

CHOllet, D.; PELAYO, P.; DELAPLACE, C.; TOURNY, C.; SIDNEY, M. Stroking characteristic variations in the 100-m freestyle for males of differing skill. Perceptual and Motor Skills, Missoula, v.85, p.167-177, 1997.

CONNOLLY, K.J. The of motor skill development. Journal of Human Moviment Studies, London, v.3, p.124-28, 1977.

. Movement, action and skill. In: HOLT, K.S. (Ed). Movement and child development. London: William Heineman, 1975

CORDAIN, L.; TUCKER, A.; MOON, D.; STAGER, J. M. Lung volumes and maximal respiratory pressures in collegiate swimmers and runners. Research Quarterly for Exercise and Sport, Washington, v.61, p.70-74, 1990. 
CORRÊA, U. C. Estrutura de prática e processo adaptativo na aquisição de habilidades motoras. 2001. Tese (Doutorado) - Escola de Educação Física e Esporte, Universidade de São Paulo, São Paulo.

CORRÊA, U. C.; TANI, G. Estrutura de prática e processo adaptativo em aprendizagem motora: por uma nova abordagem da prática. In: TANI, G. (Ed.). Comportamento Motor: aprendizagem e desenvolvimento. Rio de Janeiro: Guanabara Koogan, 2005. p.141-61.

CRAIG, A. B. Breathing holding during the turn in competitive swimming. Medicine and Science in Sports and Exercise, Madison, v.18, n.4, p.402-07, 1986.

CREIGHTON, D.L.; MORGAN, A.L.; BOARDLEY, D.; BROLINSON, P.G. Weight-bearing exercise and markers of bone turnover in female athletes. Journal of Applied Physiology, Stanford, v.90, n.2, p.565-70, 2001.

CROSSMAN, E.R.F.W. A theory of the acquisition of speed skill. Ergonomics, London, v.2, p.153-166, 1959.

D'ACQUISTO, L. J.; BERRY, J. E. Relationship between estimated propelling efficiency, peak aerobic power, and swimming performance in trained male swimmers. Medicine and Science in Sports and Exercise, Madison, v.34, n.5, p.193, 2003.

DALGAARD, P. Introductory statistics with R. New York: Springer, 2002.

DESCHODT, V. J. Relative contribution of arms and legs in humans to propulsion in 25-m sprint front-crawl swimming. European Journal of Applied Physiology and Occupational Physiology, Berlin, v.80, p.192-199, 1999.

FITTS, P.; POSNER, M. Human performance. Belmont: Brooks Cole, 1967. 
FREUDENHEIM, A.M. Organização hierárquica de um programa de ação e a estabilização de habilidades motoras. 1999. Tese (Doutorado) - Escola de Educação Física da Universidade de São Paulo, São Paulo.

FREUDENHEIM, A.M.; BASSO, L.; XAVIER FILHO, E.; SILVA, C.G.; MADUREIRA, F.; MANOEL, E. J. Organização temporal da braçada do nado crawl: iniciantes "versus" avançados. Revista Brasileira de Ciência e Movimento, v.15, n.2, 2005.

FREUDENHEIM, A.M.; GAMA, R. MOISÉS, M.; NICOLETTI, L.; CHEDID, R. A tarefa de nadar revisitada. In: SIMPÓSIO INTERNACIONAL DE CIÊNCIAS DO ESPORTE, SAÚDE E DESEMPENHO, 19., 1994, São Paulo. Anais... São Paulo: CELAFISCS, 1994. p.178.

GENTILE, A. M. A working model of skill acquisition with application to teaching. Quest, Champaign, v.17, p.3-23, 1972.

GLENCROSS, D.J. Levels and strategies of response organization. In: STELMACH, G. E.; REQUIN, J. (Eds). Tutorials in motor behavior. Amsterdam: North-Holland, 1980.

GRIMSTON, S. K.; HAY, J. G. Relationships among anthropometric and stroking characteristics of college swimmers. Medicine and Science in Sports and Exercise, Madison, v.18, p.60-68., 1986.

HOPKINS, W. G. Measures of reliability in sports medicine and science. Sports Medicine, Auckland, v.30, n.1, p.1-15, 2000.

KEPPENHAM, B. C.; YANAI, T. Limb motions and body roll in skilled and unskilled front crawl swimmers. Medicine and Science in Sports and Exercise, Madison, v.27, n.5, p.1299, 1995.

KOLMOGOROV, S.; DUPLISHEVA, A. Active drag, useful mechanical power output and hydrodynamic force coefficient in different swimming strokes at maximal velocity. Journal of Biomechanics, New York, v.25, p.311-18, 1992. 
LANGENDORFER S.J.; BRUYA L.D. Aquatic readiness. Champaign: Human Kinetics, 1995.

LERDA, R.; CARDELLI, C.; CHOLLET, D. Analysis of interaction betweem breathing and arm actions in front crawl. Journal of Human Moviment Studies, London, v.40, p.129-44, 2001.

MADUREIRA, F.; GOLLEGÃ, D.G.; FREUDENHEIM, A. M. PROPOSIÇÃO E VALIDAÇÃO DE UM INSTRUMENTO DE AVALIAÇÃO DO NADO CRAWL. MOTRIZ, RIO CLARO, V.11, N.1, P.17, 2005. (SIMPÓSIO INTERNACIONAL DE EDUCAÇÃO FÍSICA E MOTRICIDADE HUMANA).

MAGLISCHO, E.W. Nadando ainda mais rápido. São Paulo: Manole, 1999.

Swimming Fastest. Champaign: Human Kinetics, 2003.

MALINA, R.M.; BOUCHARD, C. Atividade física do atleta jovem: do crescimento à maturação. São Paulo: Roca, 2002.

MANOEL, E.J.; CONNOLLY, K.J. Variability and the development of skilled actions. International Journal of Psychophysiology,New York, v.19, p.129-147, 1995.

MENEZES, R. X. Testes para médias. In: MASSAD, E.; MENEZES, R. X.; SILVEIRA, P. S. P.; ORTEGA, N. R. S. (Ed.). Métodos quantitativos em medicina. São Paulo: Manole, 2004. p.243-75.

MILLET, G. P.; CHOLLET, D.; CHALIES, S.; CHATARD, J. C. Coordination in front crawl in elite triathletes and elite swimmers. International Journal of Sports Medicine, Stuttgard, v.23, p.99-104, 2002. 
NEWELL, K. M. Some issues on action plans. In: STELMACH, G.E. (Ed.). Information processing in motor control and learning. New York: Academic Press, 1978. p.41-54.

PEREIRA, J. C. R. Análise de dados qualitativos: estratégias metodológicas para as ciências da saúde, humanas e sociais. São Paulo: Editora da Universidade de São Paulo, 2001.

PERSYN, U.; DE MAYER, J.; VERVAEKE, H. Investigation of hydrodynamic determinants of competitive swimming strokes. In: LEWILLIE, L.; CLARYS, J.P. (Ed.). Swimming II. Champaign: Human Kinetics, 1975. p.214-22. (International Series on Sport Science).

PLATONOV, V. N.; FESSENKO, S.L. Sistema de treinamento dos melhores nadadores do mundo. Rio de Janeiro: Sprint, 2004

SANDERS, R. H. Hydrodynamics characteristics of a swimmer's hand. Journal of Applied Biomechanics, Champaign, v.15, p.3-26, 1999.

SCHIMIDT, R. A. A schema theory of discrete motor skill learning. Psychological Review, Princeton, v.82, p.225-260, 1975.

. Past an future issues in motor programming. Research Quarterly for Exercise and Sport, Washington, v. 51, p.122-140, 1980.

. The search for invariance in skilled movement behavior. Research Quarterly for Exercise and Sport, Washington, v. 56, n.2, p.188-200, 1985.

. Motor schema theory after 27 years: reflections and implications for a new theory. Research Quarterly for Exercise and Sport, Washington, v.74, n.4, pp.366-75, 2003.

SEIFERT, L., BOULESTEIX, L., CARTER, M., CHOLLET, D. The special-temporal and coordinative structures in elite male $100-\mathrm{m}$ front crawl swimmers. International Journal of Sports and Medicine, Stuttgard, v.26, p.286-93, 2005. 
SEIFERT, L.; BOULESTEIX, L.; CHOLLET, D. Effect of gender on the adaptation of arm coordination in front crawl. International Journal of Sports and Medicine, Stuttgard, v.25, p.217-23, 2004.

SEIFERT, L.; CHOLLET, D.; BARDY, B.G. Effect of swimming velocity on arm coordination in the front crawl: a dynamic analysis. Journal of Sports Sciences, London v.22, p. 651-660, 2004.

SHARP, R. L.; COSTILL, D. L. Shaving a little time. Swimming Technique, North Hollywood, v.1, p. 10-13, 1989.

TANI, G. Processo adaptativo na aprendizagem de uma habilidade perceptivo-motora. 1982. Tese (Doutorado) - Faculdade de Educação Física, Universidade de Hiroshima, Hiroshima (Resumo).

- Variabilidade de resposta e processo adaptativo em aprendizagem motora. Dissertação. 1989. Tese (Livre Docência) - Escola de Educação Física, Universidade de São Paulo, São Paulo.

Hierarchical organization of human motor behavior. Sheffield: [s.n.], 1995. (Relatório final de atividades de Pós-Doutorado, University of Sheffield).

TANI, G. (Ed.). Comportamento motor: aprendizagem e desenvolvimento. Rio de Janeiro: Guanabara Koogan, 2005.

TANI, G.; BASTOS, F.C.; CASTRO, I.J.; JESUS,J.F.; SACAY, R.C.; PASSOS, S.C.E. Variabilidade da resposta e processo adaptativo em aprendizagem motora. Revista Paulista de Educação Física, São Paulo, v.6, p. 16-25, 1992. 
TANI, G.; FREUDENHEIM, A. M.; MEIRA JÚNIOR, C. M.; CORRÊA, U. C. Aprendizagem motora: tendências, perspectivas e aplicações. Revista Paulista de Educação Física, São Paulo, v.18, p. 55-72, 2004.

THORNTON, N.; HANNULA, D. The swim coaching bible. Champaign: Human Kinetics, 2001.

TOUSSAINT, H. M.; BEEK, P.J. Biomechanics of competitive front crawl swimming. $\underline{\text { Sports }}$ Medicine, Auckland, v.13, n.1, p.8-24, 1992.

TOUSSAINT, H. M.; KNOPS, W.; DE GROOT, G.; HOLLANDER, A. P. The mechanical efficiency of front crawl swimming. Medicine and Science in Sports and Exercise, Madison, v.22, p.402-408, 1990.

UGRINOWITSCH, H. Efeito do nível de estabilização do desempenho e do tipo de perturbação no processo adaptativo em aprendizagem motora. 2003. Tese (Doutorado) Escola de Educação Física e Esporte, Universidade de São Paulo, São Paulo.

VORONTSOV, A. R.; RUMYANTSEV, V. A. Forças resistivas na natação. In ZATSIORSKY, V. M. (Ed.) Biomecânica do esporte: performance do desempenho e prevenção de lesão. Rio de Janeiro: Guanabara Koogan, 2004.

XAVIER FILHO, E. $\underline{O}$ efeito das restrições da tarefa e do ambiente no comportamento de locomoção no meio aquático. 2001. Dissertação (Mestrado) - Escola de Educação Física e Esporte, Universidade de São Paulo, São Paulo.

XAVIER FILHO, E.; BASSO, L. Variabilidade dos aspectos absolutos e relativos do movimento na braçada do nado crawl: um estudo metodológico. In: SEMINÁRIO DO 
COMPORTAMENTO MOTOR, 2., 2000, São Paulo. Anais... São Paulo: LACOM/EEFUSO, 2000.

XAVIER FILHO, E.; BASSO, L.; FREUDENHEIM, A M.; SERRA, R. M.; MADUREIRA, F. Aspectos temporais da braçada do nado de crawl: iniciantes versus avançados. In: SEMINÁRIO DO COMPORTAMENTO MOTOR, 3., 2002, Gramado. Anais... Porto Alegre: UFRGS, 2002.

WEIR, J. P. Quantifying test-retest reliability using intraclass correlation coefficient and the SEM. Journal of Strength and Conditioning Research, Champaign, v.19, n.1, p.231-40, 2005.

YANAI, T. Stroke frequency in front crawl: its mechanical link to the fluid forces required in non-propulsive directions. Journal of Biomechanics, New York, v.36, p.53-62, 2003.

ZOELLER, R. F.; NAGLE, E. F.; MOYNA, N. M.; GOSS, F. L.; LEPHART, S. M.; ROBERTSON, R. J. Anaerobic indices of freestyle swimming performance in trained adult female swimmers. Medicine and Science in Sports and Exercise, Madison, v.30, n.5, p.280, 1998.

ANEXO I - Termo de consentimento livre e esclarecido.

\author{
ESCOLA DE EDUCAÇÃO FÍSICA E ESPORTE \\ UNIVERSIDADE DE SÃO PAULO \\ TERMO DE CONSENTIMENTO LIVRE E ESCLARE CIDO
}

Easy PDF Creator is professional software to create PDF. If you wish to remove this line, buy it now. 


\section{I - DADOS DE IDENTIFICAÇÃO DO SUJ EITO DA PESQUISA E DO RESPONSÁVEL LEGAL}

1.NOME DO INDIVÍDUO

DOCUMENTO DE IDENTIDADE № :

SEXO : .M F

DATA NASCIMENTO: ........................

ENDERECO

CIDADE

№

BAIRRO:

.

CEP:

APTO

TELEFONE: DDD (.......

2.RESPONSÁVEL LEGAL:

NATUREZA (grau de parentesco, tutor, curador, etc.)

DOCUMENTO DE IDENTIDADE :

SEXO: $M \quad F$

DATA NASCIMENTO.: .....................

ENDEREÇO: №

BAIRRO: CIDADE: APTO:

TELEFONE: DDD ( ). CEP:

\section{II - DADOS SOBRE A PESQUISA CIE NTÍFICA}

1. Este projeto intitula-se "Efeito da modificação da tarefa na braçada do nado crawl em indivíduos com níveis de habilidades distintos"

2. PESQUISADOR RESPONSÁVEL: Profa. Dra. Andrea Michele Freudenheim

3. CARGO/FUNÇÃO: Professor Assistente Doutor

4. AVALIAÇÃO DO RISCO DA PESQUISA: RISCO MÍNIMO

(probabilidade de que o indivíduo sofra algum dano como consequência imediata ou tardia do estudo)

5. DURAÇÃO DA PESQUISA: 30-40 minutos.

ANE XO I - Termo de consentimento livre e esclarecido (cont.).

III - EXPLICAÇÕES DO PESQUISADOR AO INDIVÍDUO OU SEU REPRESENTANTE LEGAL SOBRE A PESQUISA, CONSIGNANDO:

1. Esse estudo é necessário para conhecer as características da habilidade do nadar a partir da visão de complementariedade entre consistência e flexibilidade do comportamento motor habilidoso. O objetivo do estudo é verificar o efeito da 
modificação da tarefa na braçada do nado crawl em indivíduos em níveis de habilidades distintos.

2. Para investigar o problema, inicialmente a criança será submetida a testes antropométricos e de composição corporal. O primeiro terá como finalidade estudar a magnitude da possível influencia do comprimento dos segmentos na tarefa, já o segundo tem o propósito de analisar o índice massa corpórea e sua possível influencia na flutuabilidade do indivíduo, fator este que pode também influenciar na execução da tarefa. Em seguida, a criança realizará 3 percursos de 30 metros nadando crawl, com intervalo de 10 minutos entre as mesmas, segundo instruções fornecidas pelo pesquisador. Durante a execução dos percursos serão coletados os dados para a análise temporal das braçadas e seus possíveis ajustes nas três velocidades, variáveis estas que podem diferenciar indivíduos mais ou menos habilidosos.

3. Não são esperados desconfortos ou riscos, pois as crianças que farão parte da amostra participam de treinamento regular que inclui um volume médio de distância nadada diariamente igual a 800 metros, sendo que no experimento nadarão apenas 90 metros. Como todos possuem liberação médica prévia, não se espera riscos envolvendo a integridade dos participantes.

4. Os participantes poderão se beneficiar obtendo mais informações sobre sua mecânica de nado em diferentes velocidades, bem como, a análise de sua composição corporal.

\section{IV - ESCLARECIMENTOS DADOS PELO PESQUISADOR SOBRE GARANTIAS DO SUJ EITO DA PESQUISA:}

- Acesso, a qualquer tempo, às informações sobre procedimentos, riscos e benefícios relacionados á pesquisa, inclusive para dirimir eventuais dúvidas: A criança e seu responsável podem, em qualquer momento, obter a informação que desejarem à respeito de procedimentos, eventuais riscos e benefícios relacionados à pesquisa;

- Liberdade de retirar seu consentimento a qualquer momento e de deixar de participar do estudo, sem que isto traga prejuízo à continuidade da assistência: A criança e seu responsável têm a liberdade de retirar seu consentimento e deixar de participar do estudo, sem nenhum prejuízo;

- Salvaguarda da confidencialidade, sigilo e privacidade: Nenhuma informação a respeito da identidade da criança ou do responsável serão tornadas públicas;

- Disponibilidade de assistência por eventuais danos à saúde, decorrentes da pesquisa, será feita inicialmente pelo médico plantonista da instituição onde serão realizados os testes e pelo Hospital Pronto Socorro Infantil Gonzaga e Santa Casa de Misericórdia de Santos.

ANEXO I - Termo de consentimento livre e esclarecido (cont.).

\section{V - INFORMAÇÕES DE NOMES, ENDEREÇOS E TELEFONES DOS RESPONSÁVEIS PELO ACOMPANHAMENTO DA PESQUISA, PARA CONTATO EM CASO DE INTERCORRÊ NCIAS CLÍNICAS E REAÇÕES ADVERSAS.}

Pesquisador gerente: Fabrício Madureira Barbosa - telefone: (0XX13) 32325564

Pesquisador responsável: Andréa Michele Freudenheim - Telefone: (0XX19) 38469579 


\section{VII - CONSE NTIME NTO PÓS-E SCLARE CIDO}

Declaro que, após convenientemente esclarecido pelo pesquisador e ter entendido o que me foi explicado, consinto em meu filho participar do presente Projeto de Pesquisa

São Paulo, de de 2005

Assinatura do responsável legal

Assinatura do pesquisador

(carimbo ou nome legível)

\section{INSTRUÇÕES PARA PREE NCHIME NTO \\ (Resolução Conselho Nacional de Saúde 196, de 10 outubro 1996)}

1. Este termo conterá o registro das informações que o pesquisador fornecerá ao sujeito da pesquisa, em linguagem clara e accessível, evitando-se vocábulos técnicos não compatíveis com o grau de conhecimento do interlocutor.

2. A avaliação do grau de risco deve ser minuciosa, levando em conta qualquer possibilidade de intervenção e de dano à integridade física do sujeito da pesquisa.

3. O formulário poderá ser preenchido em letra de forma legível, datilografia ou meios eletrônicos.

4. Este termo deverá ser elaborado em duas vias, ficando uma via em poder do paciente ou seu representante legal e outra deverá ser juntada ao prontuário do paciente.

5. A via do Termo de Consentimento Livre e Esclarecido submetida à análise do Comitê de Ética em Pesquisa - CEP deverá ser idêntica àquela que será fornecida ao sujeito da pesquisa.

ANE XO II - Instrumento para análise do nível de proficiência do nado crawl.

\section{1) Erros na Recuperação e Entrada:}

- Braço sobre a água com movimento baixo e amplo, oscilando o corpo -

$\operatorname{BrD}()$ e $\operatorname{BrE}(\quad)$

- Mãos posicionadas acima do cotovelo - $\operatorname{Br} D($ ) e $\operatorname{BrE}($ )

- Extensão do braço antes de sua entrada na água - $\operatorname{Br} D(\quad$ ) e $\operatorname{Br} E(\quad$ )

- Braço desalinhado com o ombro durante a entrada na água no sentido horizontal - 
$\operatorname{BrD}(\quad)$ e $\operatorname{BrE}(\quad)$

- Entrada da mão na água, próximo a cabeça - $\operatorname{Br} D($ ) e $\operatorname{Br} E(\quad$ )

- Palma da mão virada para baixo durante a entrada na água - $\operatorname{Br} D($ ) e $\operatorname{Br} E($ )

2) Erros de Liberação:

- Palma da mão voltada para cima durante a finalização da braçada -

$\operatorname{Br} \mathrm{D}(\quad)$ e $\operatorname{Br} E(\quad)$

- Palma da mão voltada para fora durante a liberação - Br D ( ) e BrE ( )

- Submersão do braço estendido - Br D( ) e BrE ( )

- Dorso da mão voltado para cima na finalização - $\operatorname{Br} D($ ) e $\operatorname{Br} E($ )

3) Erros de Sincronização das braçadas:

- Início precoce da varredura para baixo - $\operatorname{Br} D($ ) e $\operatorname{BrE}($ )

- Deslize do braço na água durante a entrada do mesmo - $\operatorname{Br} D($ ) e $\operatorname{BrE}($ )

- Quebra da continuidade do movimento no início da braçada -

$\operatorname{BrD}(\quad)$ e $\operatorname{BrE}(\quad)$

- Quebra da continuidade do movimento no final da braçada - Br D( ) e BrE ( )

- Diferença no traçado propulsivo das braçadas ( ).

- Diferença na velocidade de propulsão entre os braços ( ).

4) Erros de Respiração:

- Processo respiratório incompatível com o esforço ( ).

- Insuficiente rotação do tronco e quadril ( ).

- Projeção da cabeça para trás no momento da respiração ( ).

- Rotação da face cedo demais ( ).

- Rotação da face tarde demais ( ).

- Extensão da coluna cervical durante a imersão do rosto na água ( ).

ANEXO II - Instrumento para análise do nível de proficiência do nado crawl (cont.).

\section{5) Erros de Sincronização entre as Braçadas e a Respiração}

- Quebra do ritmo das braçadas no momento da respiração ( ).

- Início do processo respiratório durante a fase aérea do braço onde ocorre a respiração ( ) . 
- Término do processo respiratório durante a entrada da mão na água pelo braço onde ocorre a respiração ( ).

- Freqüência respiratória incompatível com o ritmo de braçadas ( ).

6) Erros da Varredura para Baixo:

- Início da força propulsiva com o cotovelo abaixo da mão - $\operatorname{Br} D($ ) e $\operatorname{BrE}($ )

- Deslize da mão demasiadamente para fora na varredura - $\operatorname{BrD}($ ) e $\operatorname{BrE}($ )

- Palmateio com a palma da mão virada totalmente para baixo - $\mathrm{Br} \mathrm{D}($ ) e $\mathrm{BrE}($ )

7) Erros da Varredura para Dentro:

- Propulsão da mão sem mudança na sua inclinação - $\operatorname{BrD}($ ) e $\operatorname{Br} E($ )

- Inclinação excessiva da mão, sendo perpendicular à sua direção $\mathrm{BrD}($ ) e BrE ( )

- Cotovelo cruza internamente o alinhamento do ombro - $\mathrm{BrD}($ ) e BrE ( )

- Cotovelo muito flexionado durante a propulsão - $\operatorname{BrD}($ ) e $\operatorname{Br} E($ )

- Cotovelo pouco flexionado durante a propulsão - BrD( ) e BrE ( )

8) Erros da Varredura para Cima:

- Ausência da hiperextensão do punho na finalização da braçada $\mathrm{BrD}($ ) e BrE ( )

- Desaceleração do braço na finalização da propulsão - $\operatorname{BrD}($ ) e BrE ( )

- Finalização precoce da varredura - $\mathrm{BrD}($ ) e $\operatorname{BrE}($ )

\section{9) Erros no Posicionamento do Corpo:}

- Hiperextensão da coluna, posicionando o corpo excessivamente fora da água ( ).

- Hiperextensão da coluna, com rebaixamento do quadril ( ).

- Ausência de rolamento do tronco e quadril ( ).

- Rolamento do tronco e quadril unilateral ( ).

- Desalinhamento látero - lateral, nado serpenteante ( ).

- Pernadas muito profundas, aumento do espaço ocupado pelo corpo ( ).

ANEXO II - Instrumento para análise do nível de proficiência do nado crawl (cont.).

\section{0) Erros de Pernadas:}

- Recuperação das pernas demasiadamente elevadas ( ).

- Propulsão demasiadamente profunda ( ). 
- Movimentos somente no plano vertical ( ).

- Flexão excessiva os joelhos ( ).

- Flexão plantar, insuficiente dos tornozelos durante a propulsão ( ).

- Tornozelo sem rotação interna durante as fases propulsivas ( ).

- Diferença no traçado propulsivo das pernadas ( ).

- Diferença na velocidade de propulsão entre as pernas ( ).

\section{1) Erros de Sincronização entre as Pernadas e a Respiração}

- Quebra do ritmo de pernadas no momento da respiração ( ).

- Alteração na amplitude das pernadas durante a rotação do tronco no processo respiratório ( ).

- Freqüência respiratória incompatível com o ritmo de pernadas ( ).

12) Erros de Sincronização entre as Pernadas e as Braçadas

- Baixo ritmo de pernadas para braçadas curtas ( ).

- Alto ritmo de pernadas induzindo a diminuição na coordenação das braçadas ( ).

- Alto ritmo de braçadas induzindo a diminuição na coordenação das pernadas ( ).

ANE XO III - Ilustrações do aparelho usado para captar as imagens, aérea e subaquática, para a análise qualitativa do nado. 


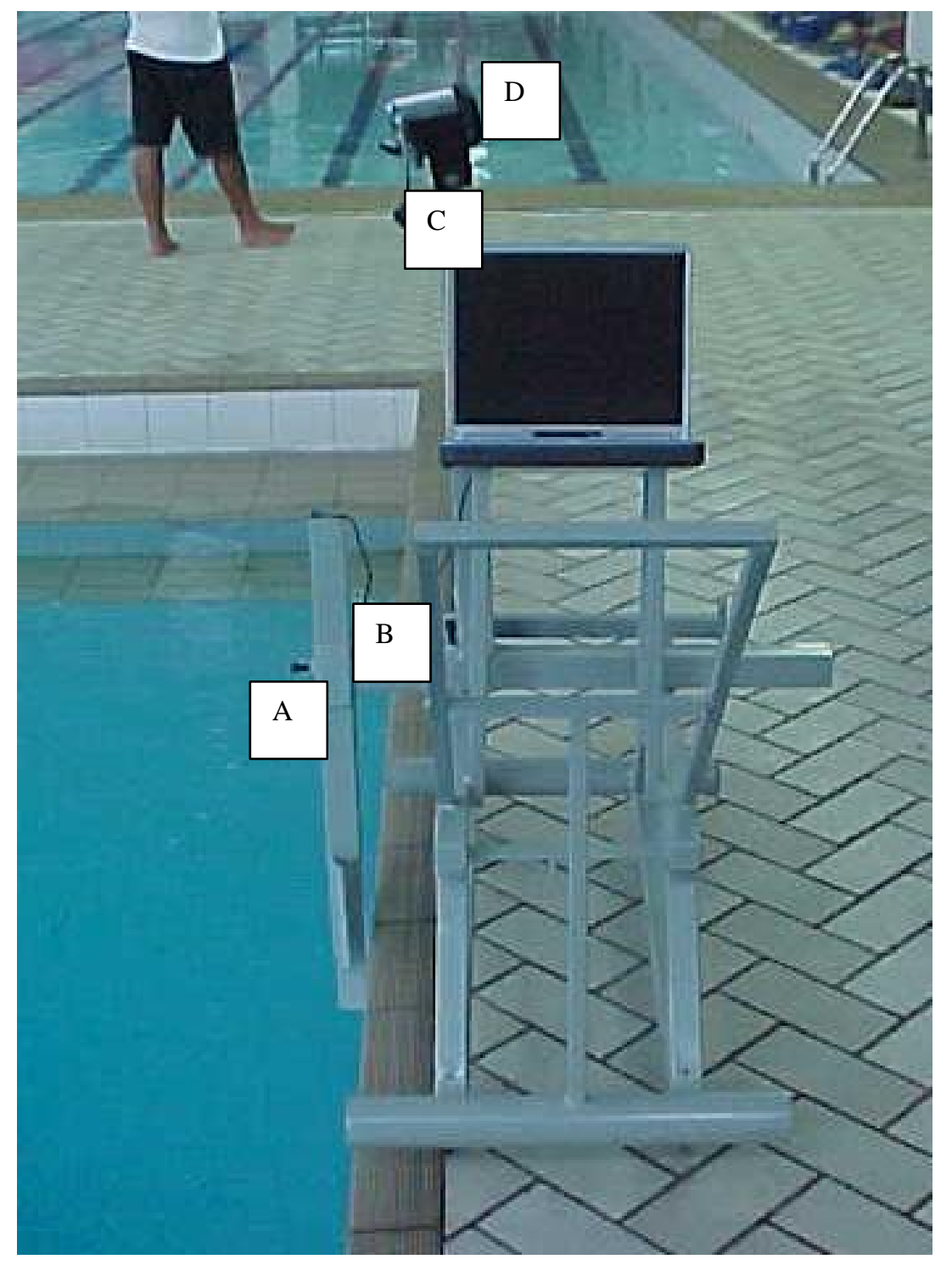

ANE XO IV - Descrição do aparelho usado para captar as imagens aérea e subaquática, para a análise qualitativa do nado

Easy PDF Creator is professional software to create PDF. If you wish to remove this line, buy it now. 
O carro e filmagem dinâmica aquática, tem massa estrutural total de $40 \mathrm{~kg}$, comprimento de 1 metro e 40 centímetros e altura de 1 metro e 52 centímetros. O mesmo possui quatro ajustes manuais, que são identificados na figura com as letras $A, B, C$ e D. $O$ ajuste A é o telescópio do aparelho e pode ser submerso até a profundidade de 80 centímetros, com o potencial de adaptado ao mesmo, novos prolongadores de profundidade. O ajuste $\mathrm{B}$ é o braço prolongador do telescópio no eixo horizontal, o mesmo se afasta do carro 80 centímetros e foi elaborado para ser usado em piscina que tem declive no meio metro inicial, muito comum nas piscinas modernas para evitar água parada. $\mathrm{O}$ ajuste $\mathrm{C}$ permite a câmera aérea ser posicionada em ângulos de até 180 graus no eixo vertical e finalmente o ajustador $D$ permite uma variação de espessuras de câmeras para afixá-las na barra vertical.

Quanto ao telescópio do parelho, foram construídos bordos de ataque a água em suas laterais, com 30 graus de inclinação, com o objetivo de diminuir a resistência do aparelho em deslocamento, bem como evitar o surgimento de bolhas de ar resultantes do arrasto de forma.

Os trilhos foram construídos por pares de 2 metros de cantoneiras de $3 / 4$ que eram fixas a cada metro no eixo vertical, desta forma, o carro era deslocado para frente e para trás sem tremulações da imagem ou alterações de direção do carro no sentido lateral.

ANEXO V - Distribuição dos aspectos invariantes das braçadas do braço direito nas fases aérea e aquática, para ambos os grupos. 


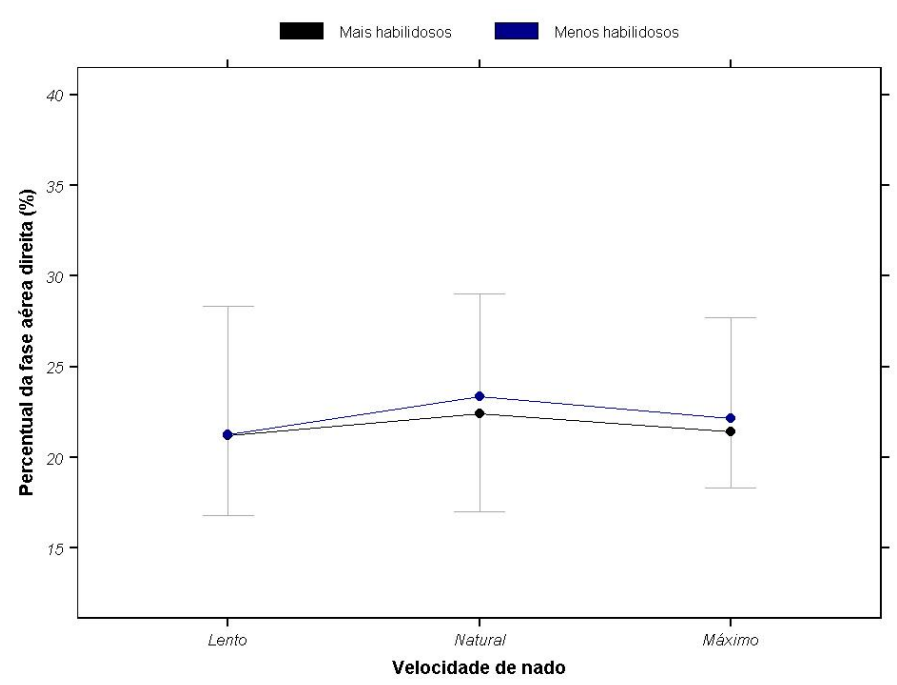

Figura 1. Descrição e comparação do percentual da fase aérea do braço direito entre os grupos mais e menos habilidosos. Os círculos ( ) indicam a média e as barras de erro os desvios padrões.

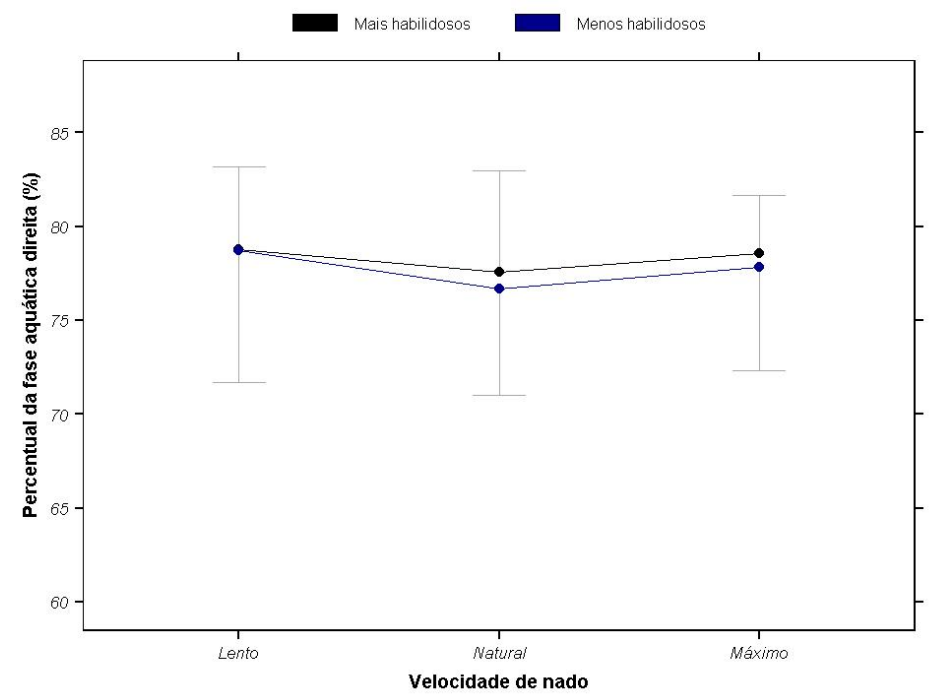

Figura 2. Descrição e comparação do percentual da fase aquática do braço direito entre os grupos mais e menos habilidosos. Os círculos ( ) indicam a média e as barras de erro os desvios padrões.

ANE XO VI - Distribuição dos aspectos invariantes das braçadas do braço esquerdo (fase aérea e aquática) para ambos os grupos. 


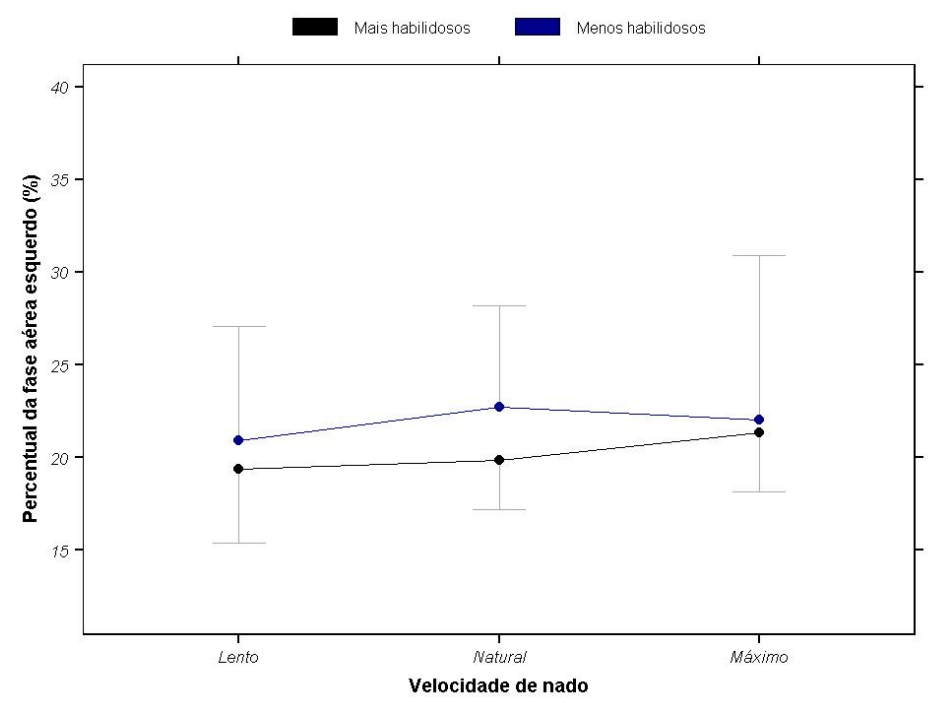

Figura 3. Descrição e comparação do percentual da fase aérea do braço esquerdo entre os grupos mais e menos habilidosos. Os círculos ( ) indicam a média e as barras de erro os desvios padrões.

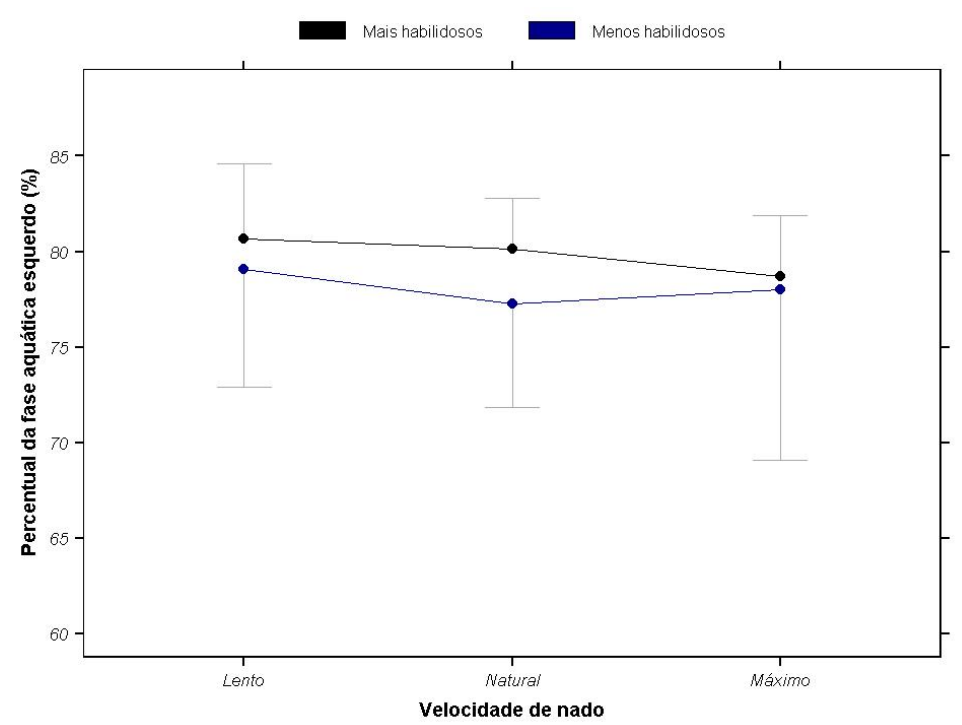

Figura 4. Descrição e comparação do percentual da fase aquática do braço esquerdo entre os grupos mais e menos habilidosos. Os círculos ( ) indicam a média e as barras de erro os desvios padrões.

ANE XO VII - Variabilidade dos aspectos invariantes do braço direito nas fases aérea e aquática em ambos os grupos. 


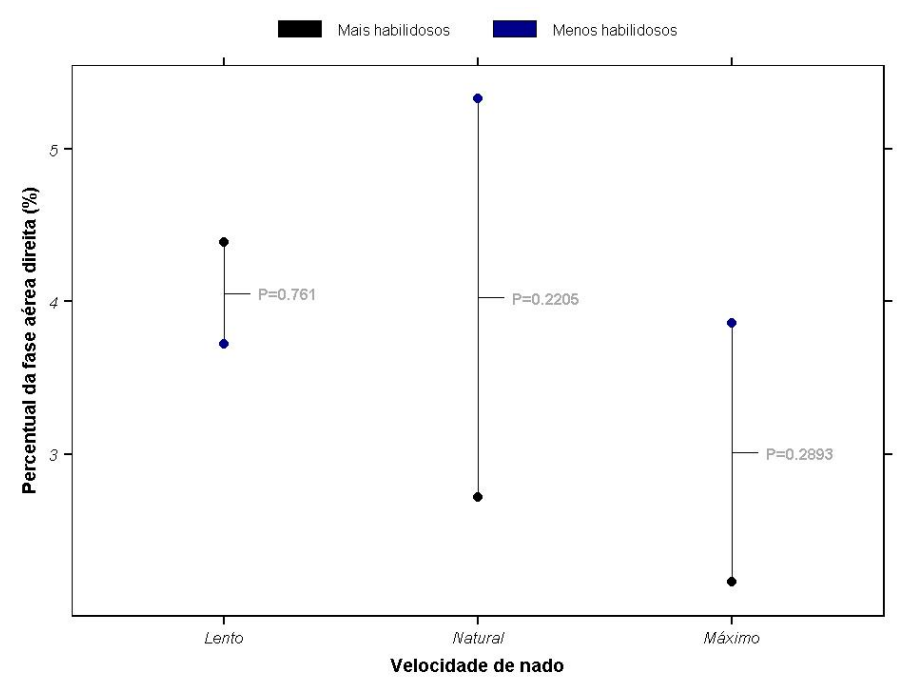

Figura 5. Descrição e comparação do erro típico da medida para percentual da fase aérea do braço direito entre os grupos mais e menos habilidosos. O círculo ( ) indica o erro típico da medida.

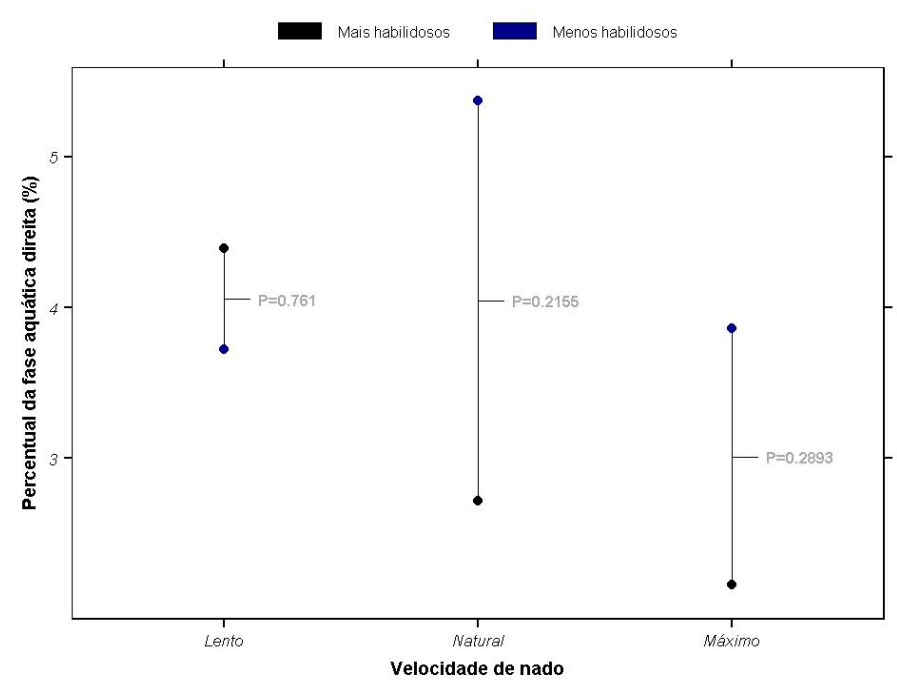

Figura 6. Descrição e comparação do erro típico da medida para percentual da fase aquática do braço direito entre os grupos mais e menos habilidosos. O círculo ( ) indica o erro típico da medida.

ANEXO VIII - Variabilidade dos aspectos invariantes do braço esquerdo nas fases aérea e aquática em ambos os grupos.

Easy PDF Creator is professional software to create PDF. If you wish to remove this line, buy it now. 


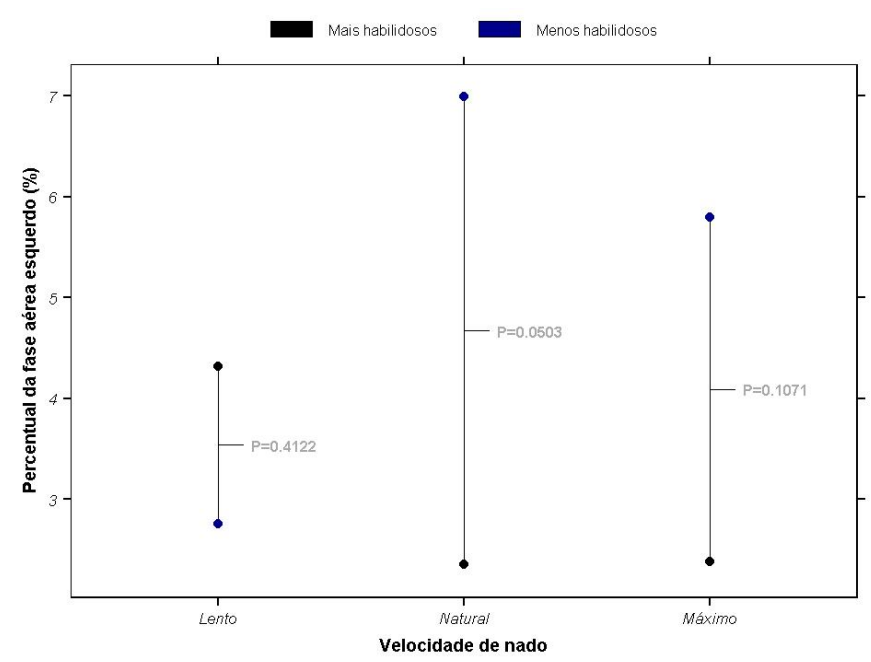

Figura 7. Descrição e comparação do erro típico da medida para percentual da fase aérea do braço esquerdo entre os grupos mais e menos habilidosos. O círculo ( ) indica o erro típico da medida.

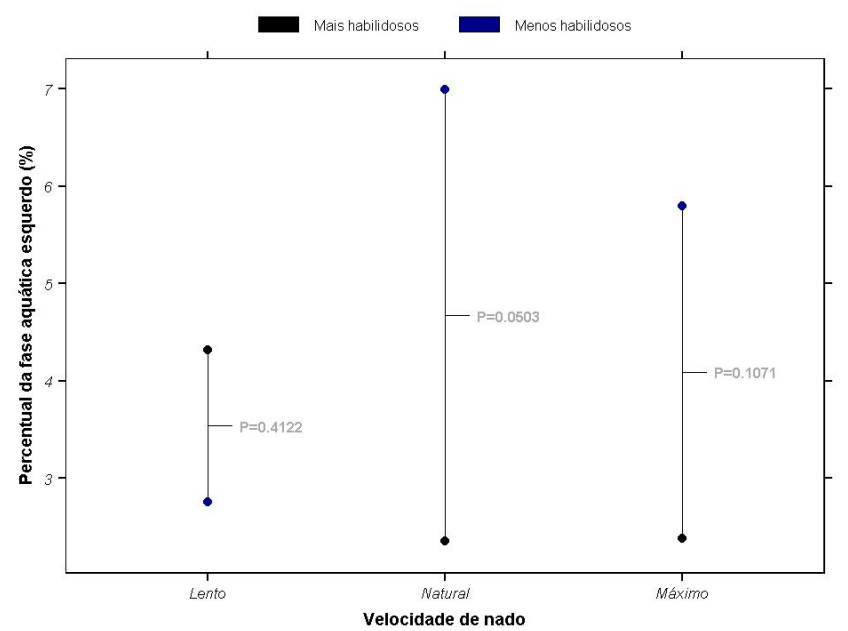

Figura 8. Descrição e comparação do erro típico da medida para percentual da fase aquática do braço esquerdo entre os grupos mais e menos habilidosos. O círculo ( ) indica o erro típico da medida.

ANEXO IX - Distribuição aspectos variantes do braço direito para as fases aérea e aquática de ambos os grupos. 


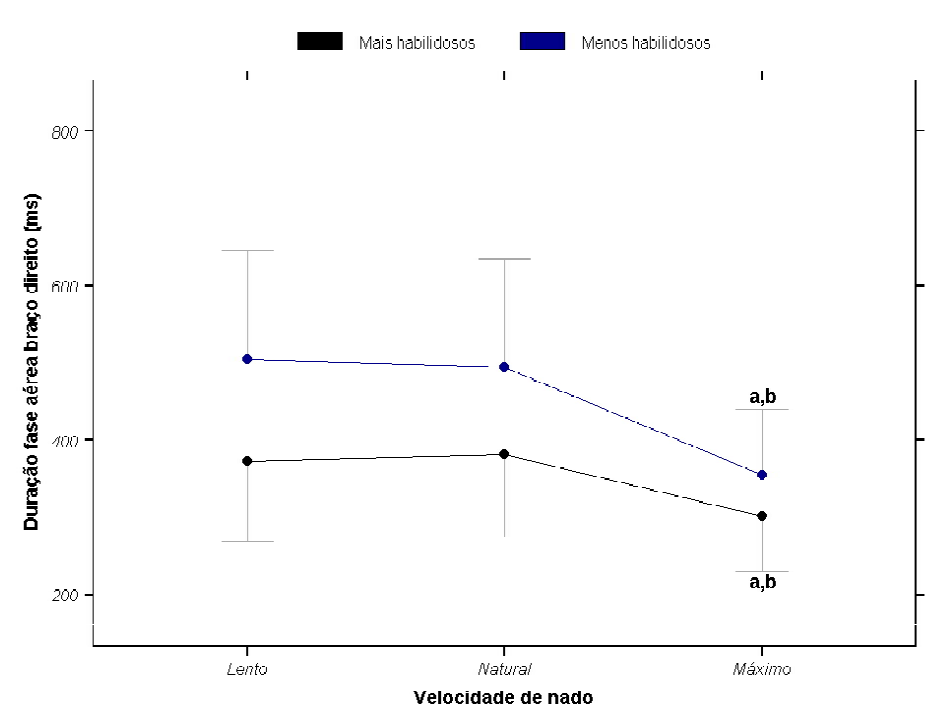

Figura 9. Descrição e comparação da duração da fase aérea do braço direito entre os grupos mais e menos habilidosos. Os círculos ( ) indicam a média e as barras de erro os desvios padrões. ${ }^{a}$ indica diferença estatisticamente significante; $\mathrm{P} \quad 0,05$; em relação ao nado lento. ${ }^{\mathrm{b}}$ indica diferença estatisticamente significante; $\mathrm{P} \quad 0,05$; em relação ao nado natural.

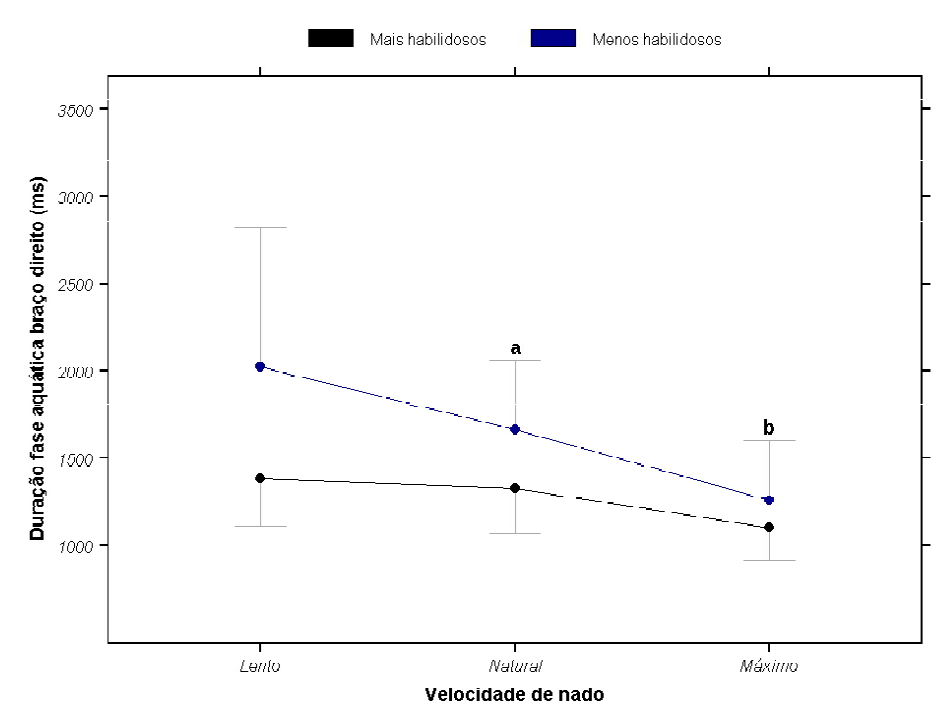

Figura 10. Descrição e comparação da duração da fase aquática do braço direito entre os grupos mais e menos habilidosos. Os círculos ( ) indicam a média e as barras de erro os desvios padrões. ${ }^{a}$ indica interação estatisticamente significante; $\mathrm{P} \quad 0,05$; entre grupos e o comportamento da passagem do nado lento para 0 nado natural. ${ }^{b}$ indica interação estatisticamente significante; $P \quad 0,05$; entre grupos e o comportamento da passagem do nado lento para o nado máximo.

ANEXO X - Distribuição aspectos variantes do braçada direita total. 


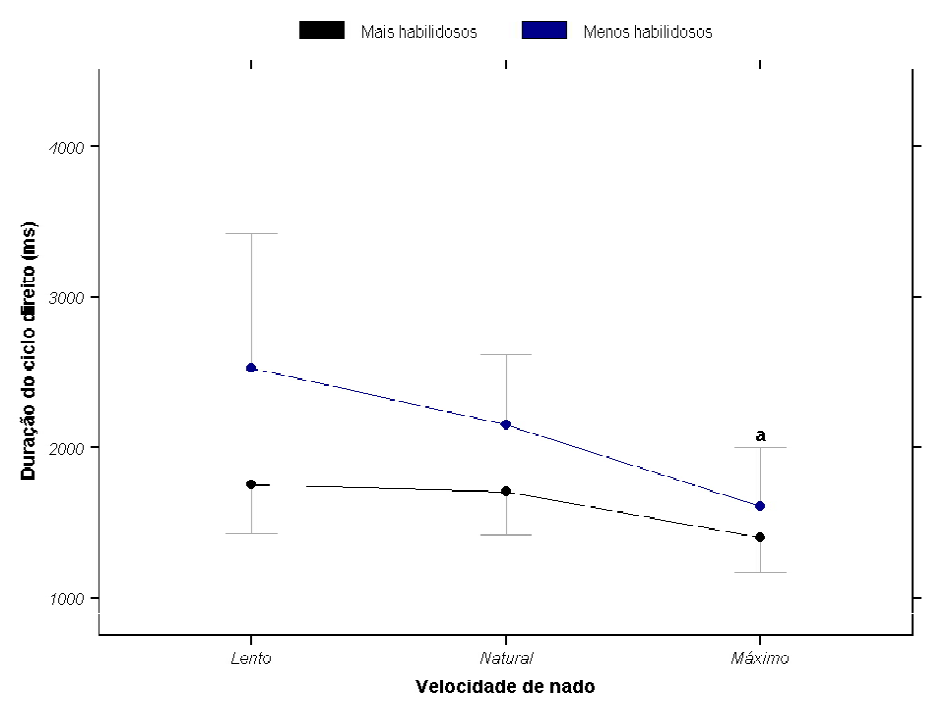

Figura 11. Descrição e comparação da duração do ciclo direito entre os grupos mais e menos habilidosos. Os círculos ( ) indicam a média e as barras de erro os desvios padrões. ${ }^{a}$ indica interação estatisticamente significante; $\mathrm{P} \quad 0,05$; entre grupos e o comportamento da passagem do nado lento para o nado máximo.

ANEXO XI - Distribuição aspectos variantes do braço esquerdo para as fases aérea e aquática de ambos os grupos.

Easy PDF Creator is professional software to create PDF. If you wish to remove this line, buy it now. 


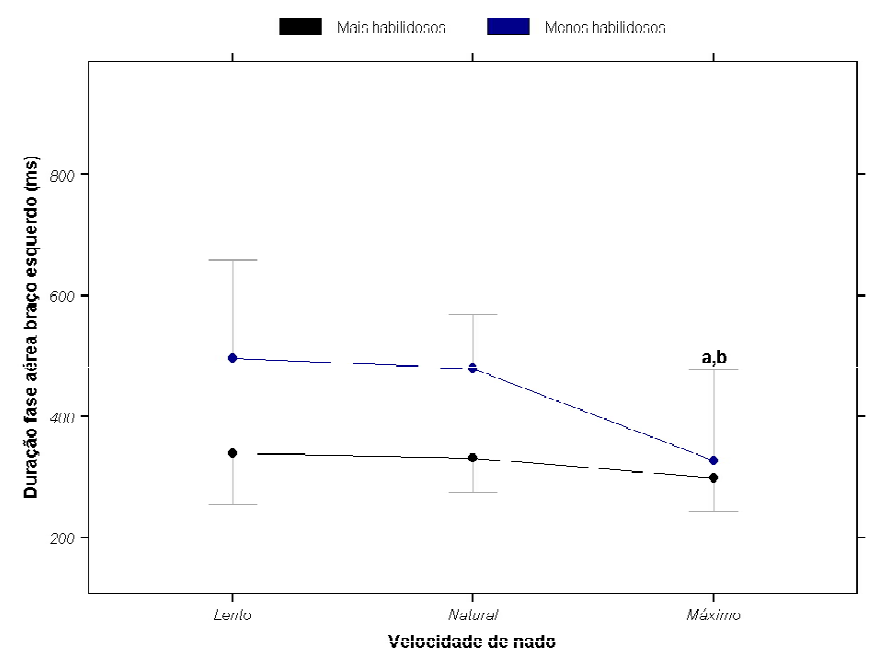

Figura 12. Descrição e comparação da duração da fase aérea do braço esquerdo entre os grupos mais e menos habilidosos. Os círculos ( ) indicam a média e as barras de erro os desvios padrões. ${ }^{a}$ indica interação estatisticamente significante; $P \quad 0,05$; entre grupos e o comportamento da passagem do nado lento para 0 nado máximo. ${ }^{b}$ indica interação estatisticamente significante; $P \quad 0,05$; entre grupos e o comportamento da passagem do nado natural para o nado máximo.

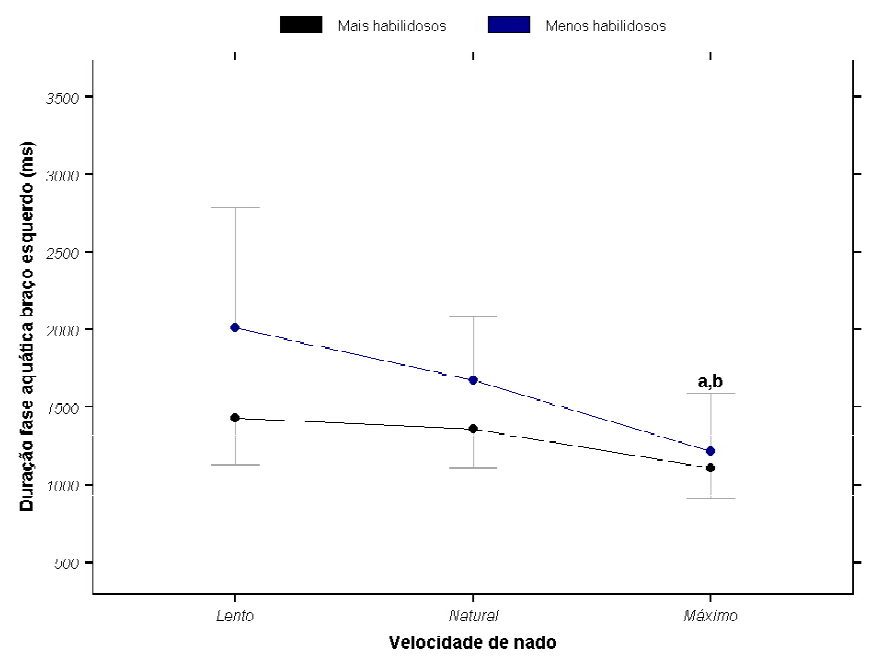

Figura 13. Descrição e comparação da duração da fase aquática do braço esquerdo entre os grupos mais e menos habilidosos. Os círculos ( ) indicam a média e as barras de erro os desvios padrões. ${ }^{a}$ indica interação estatisticamente significante; $\mathrm{P} \quad 0,05$; entre grupos e o comportamento da passagem do nado lento para 0 nado máximo. ${ }^{b}$ indica interação estatisticamente significante; $P \quad 0,05$; entre grupos e o comportamento da passagem do nado natural para o nado máximo.

ANE XO XII - Distribuição aspectos variantes do braçada esquerda total. 


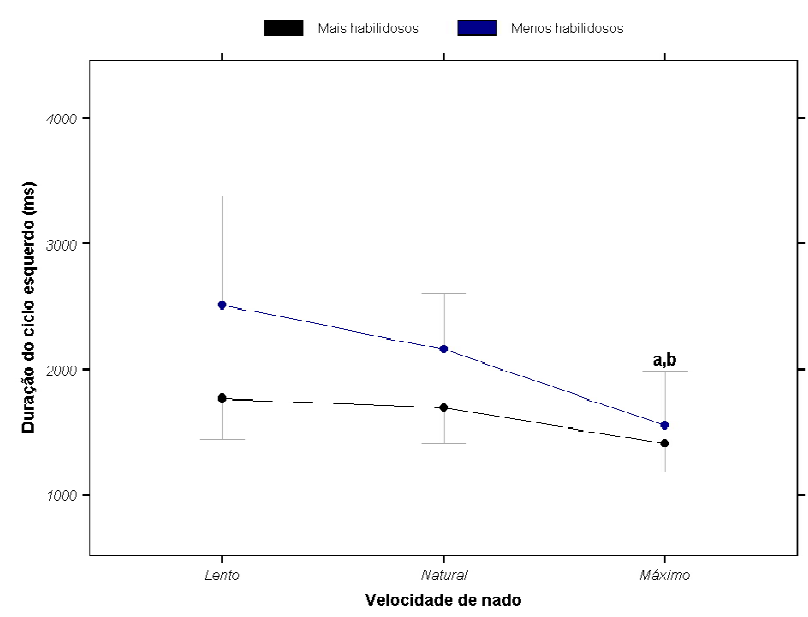

Figura 14. Descrição e comparação da duração do ciclo esquerdo entre os grupos mais e menos habilidosos. Os círculos ( ) indicam a média e as barras de erro os desvios padrões. ${ }^{a}$ indica interação estatisticamente significante; $\mathrm{P} \quad 0,05$; entre grupos e o comportamento da passagem do nado lento para o nado máximo. ${ }^{b}$ indica interação estatisticamente significante; $P \quad 0,05$; entre grupos e o comportamento da passagem do nado natural para o nado máximo.

\section{ANEXO XIII - Distribuição aspectos variantes do ciclo total}




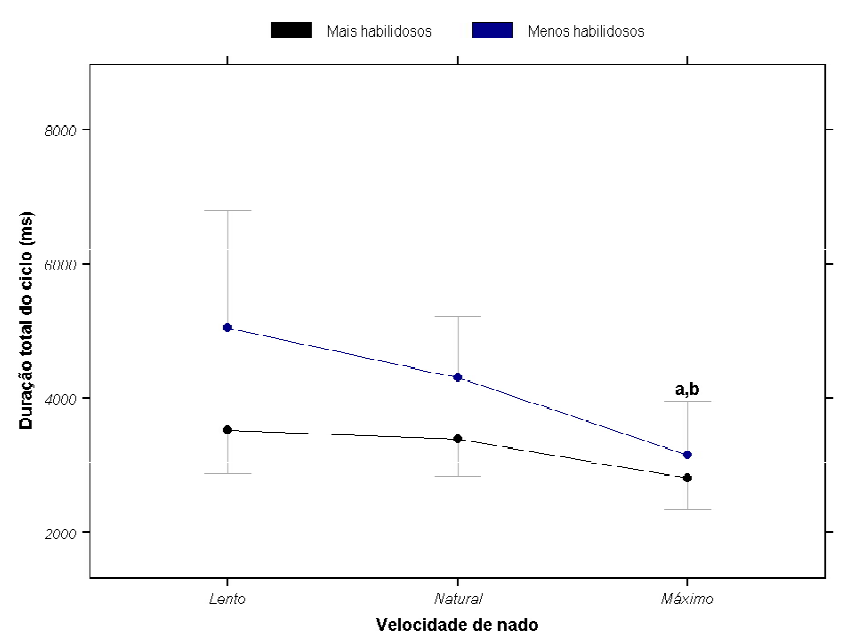

Figura 25. Descrição e comparação da duração total do ciclo de braçada entre os grupos mais e menos habilidosos. Os círculos ( ) indicam a média e as barras de erro os desvios padrões. ${ }^{a}$ indica interação estatisticamente significante; $P \quad 0,05$; entre grupos e o comportamento da passagem do nado lento para 0 nado máximo. ${ }^{\mathrm{b}}$ indica interação estatisticamente significante; $\mathrm{P} \quad 0,05$; entre grupos e o comportamento da passagem do nado natural para o nado máximo. 
ANEXO XIV - Variabilidade dos aspectos variantes da fase aérea e aquática do braço direito para ambos os grupos.

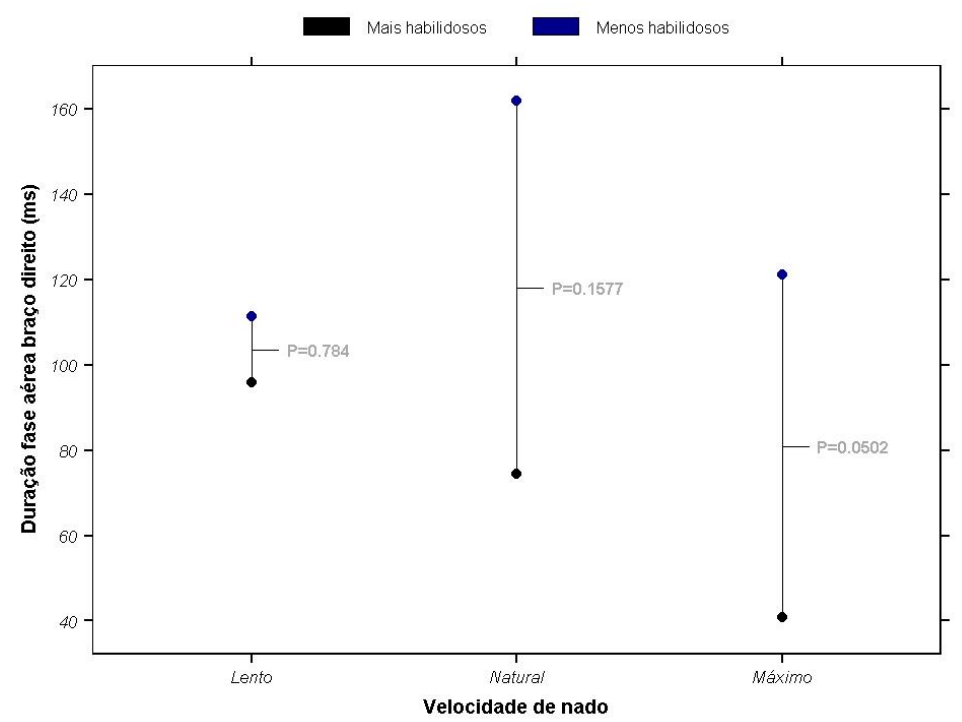

Figura 36. Descrição e comparação do erro típico da medida para duração da fase aérea do braço direito entre os grupos mais e menos habilidosos. $O$ círculo ( ) indica o erro típico da medida.

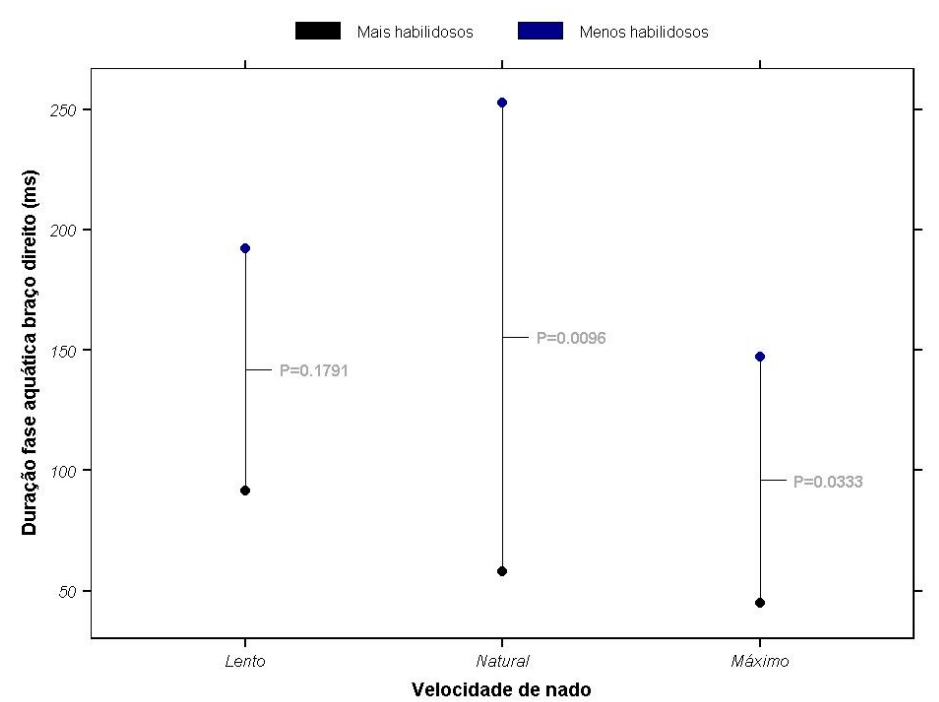

Figura 47. Descrição e comparação do erro típico da medida para duração da fase aquática do braço direito entre os grupos mais e menos habilidosos. O círculo ( ) indica o erro típico da medida. 
ANEXO XV - Variabilidade dos aspectos variantes do braço direito total.

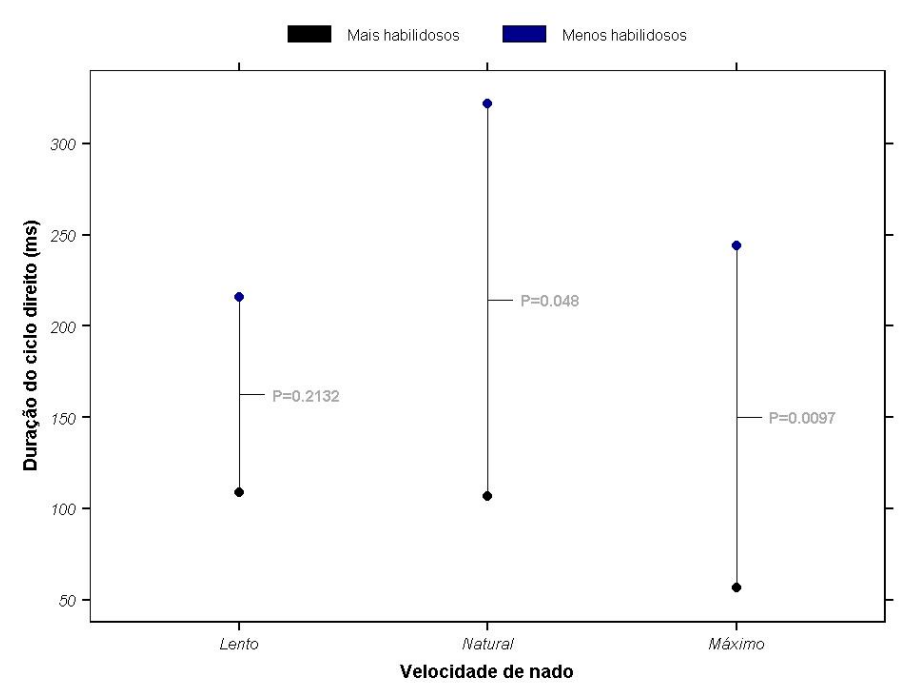

Figura 18. Descrição e comparação do erro típico da medida para duração do ciclo direito entre os grupos mais e menos habilidosos. O círculo ( ) indica o erro típico da medida. 


\section{ANE XO XVI - Variabilidade dos aspectos variantes da fase aérea e aquática do braço esquerdo para ambos os grupos.}

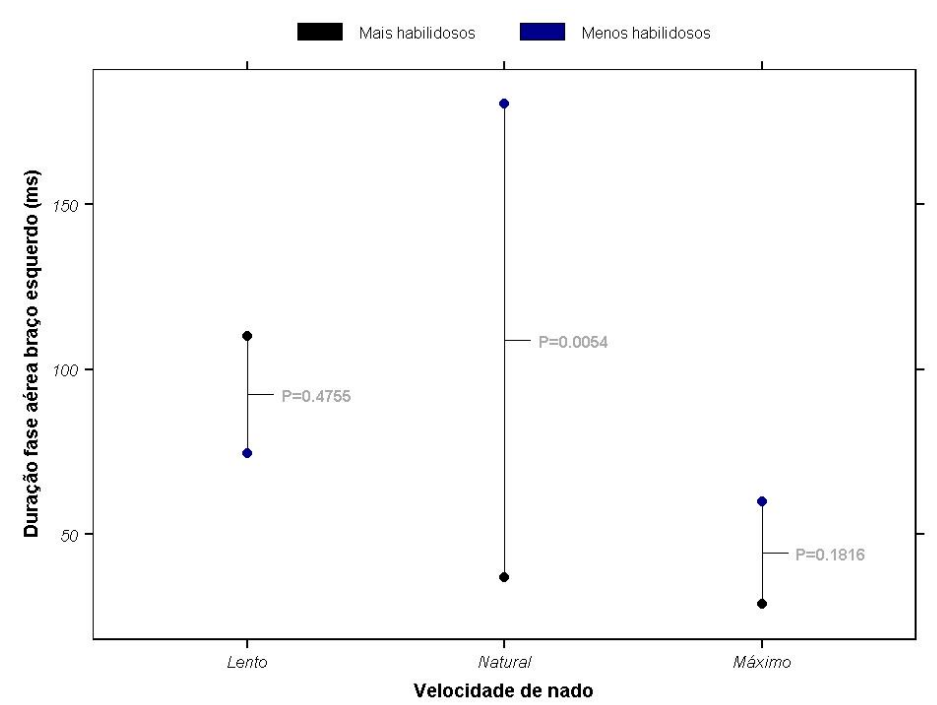

Figura 59. Descrição e comparação do erro típico da medida para duração da fase aérea do braço esquerdo entre os grupos mais e menos habilidosos. O círculo ( ) indica o erro típico da medida.

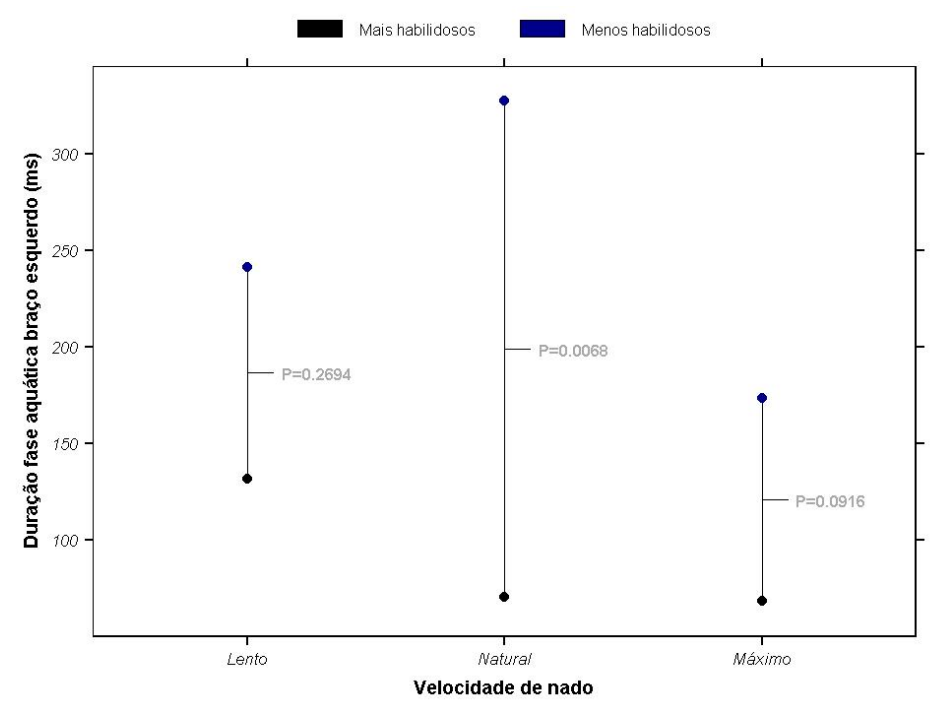

Figura 20. Descrição e comparação do erro típico da medida para duração da fase aquática do braço esquerdo entre os grupos mais e menos habilidosos. O círculo ( ) indica o erro típico da medida. 


\section{ANEXO XVII - Variabilidade dos aspectos variantes do braço esquerdo total.}

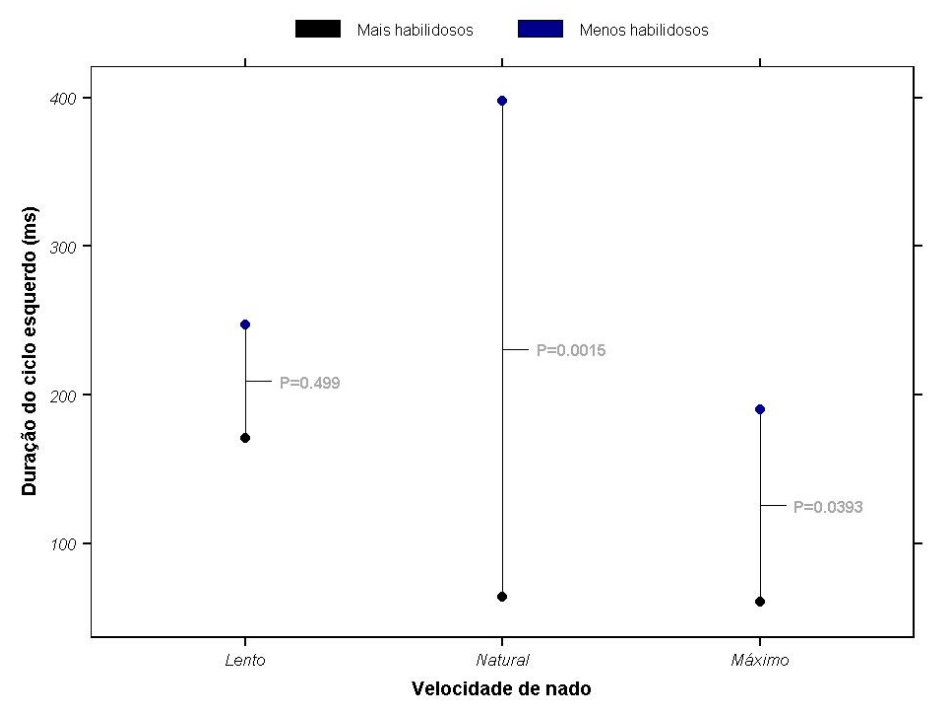

Figura 21. Descrição e comparação do erro típico da medida para duração do ciclo esquerdo entre os grupos mais e menos habilidosos. O círculo ( ) indica o erro típico da medida. 


\section{ANE XO XVIII - Variabilidade dos aspectos variantes do ciclo total das braçadas.}

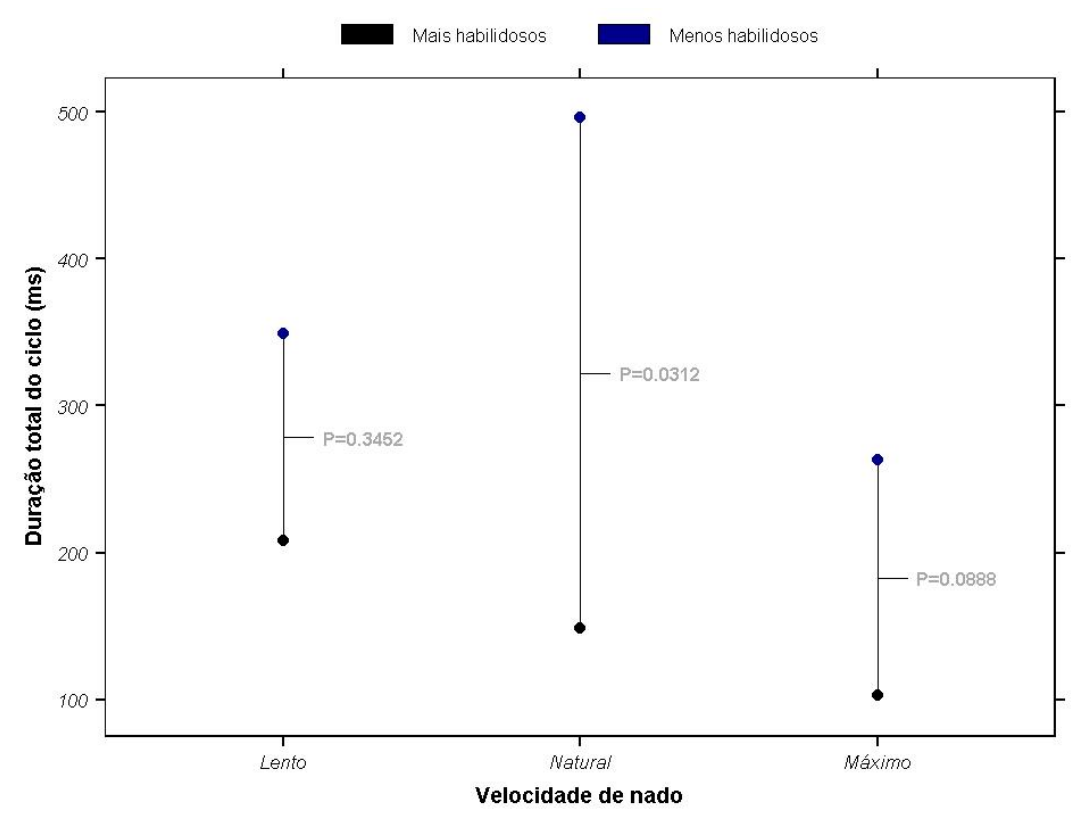

Figura 22. Descrição e comparação do erro típico da medida para duração total do ciclo de braçada entre os grupos mais e menos habilidosos. O círculo ( ) indica o erro típico da medida. 
Easy PDF Creator is professional software to create PDF. If you wish to remove this line, buy it now. 